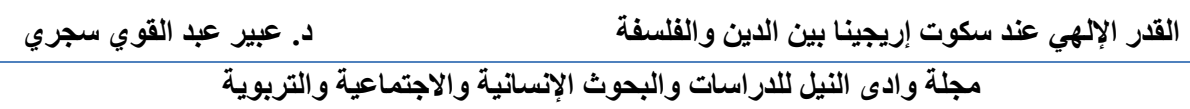

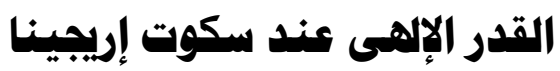

بين الدين والفالسفة

Scotus Eriugena's Divine Predestination

Between Religion and Philosophy

د. عبير عبد القوى سجرى1

المضص باللغة العربية:

تكمن إثكالية هذه الدراسة فى محاولة التعرف على ماهية موقف إريجينا من

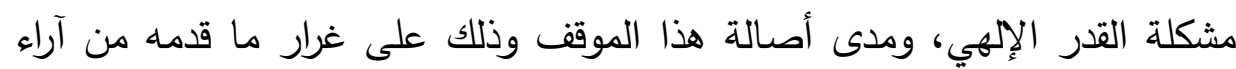
تخص اللاهوت والطبيعة.

ولقد عولنا على المنهج التحليلى النقدى المقارن للتعاطى مع موضوع هذه

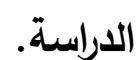

ومن خلال هذه الاراسة توصلنا إلى عدة نتائج منها:

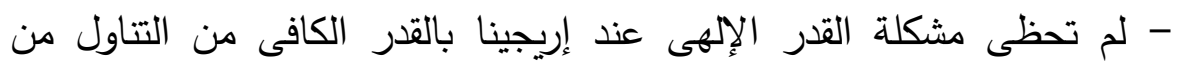
الباحثين المنشغلين بالفكر الوسيط.

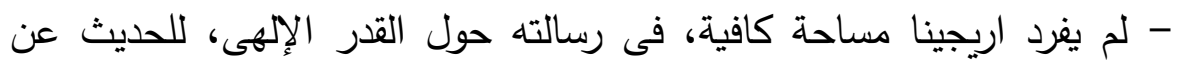

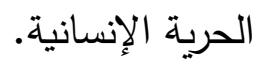

- فلقد عول إريجينا على الفلسفة والجدل بشكل مبالغ فيه ازاء معالجته لمسألة القدر الإلهى وذلك على النقيض من استخدامه للدين ونصوص الكتاب المقد.

\title{
Abstract in English:
}

The problem of this study lies in trying to identify Eriugena'strue position from Divine predestination,As well as the degree of authenticity of this position, along the lines of his own views in the theology and the nature.

1 د. عبير عبد القوى سجرى: مدرس فلسفة العصور الوسطى المسيحية، قسم الدراسات الفلسفيةكلية الآداب- جامعة عين شمس. 
مجلة وادي النيل للاراسات والبحوث الإنسانية والاجتماعية ـ مجلة علمية محكمة

(ISSN : 2536 - 9555)

We have relied on comparative analytical method to deal with the subject of this study.

And We have reached several results as:

- The problem ofEriugena'sDivine predestination was not sufficiently addressed by researchers interested in medieval thought.

- Eriugena did not apply enough space in hisTreatise On Divine Predestination to talk about human freedom.

- Eriugena's Treatment inTheproblem ofDivine predestination relied heavily on Philosophy and Dialictic and that on the contraryof the use of Religion and The texts of the Bible.

\section{الاقدهمة}

يعد يوحنا سكوت إريجينا John Scottus Eriugena* أبرز أسـاتذة القرن

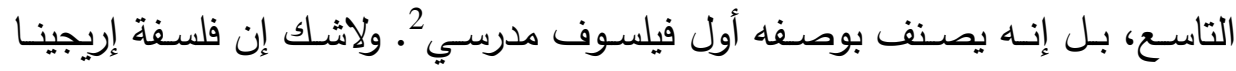

تبصرنا بمدى ما مر باه من مواقف بارزة وعتيقة، وتبرز كذلك نصرته للعقل البشرى،

وأن قوة الحوار ووحدة روح كل الرجال Men تمثل كل العناصر الضـرورية للفلسفة

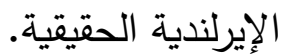

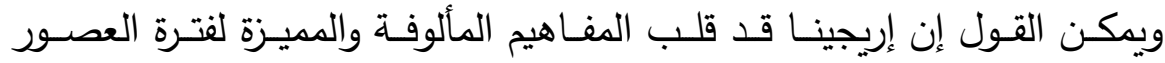

الوسطى، إذ كانت تصـف بوصفها زمنًا للتدرج السلطوى، وافتقار الأصـالة، وكذا

الخرافات العامـة، يمكن القول إن عمل إريجينا يقترب من المفاهيم المتعارف عليها

* يثير معاصـرى إريجينا لـه بإسم جوانز سكوتوس، وهذا يتضـح من خـلال مخطوطسات القرن

العاشر والقرن اللاحق عليه. ولقد تعددت أثكال كتابة اسمه، ولكن الأقدم والأكثر رواجًا وقبولًا

من الناحية اللغوية هو Eriugena، وتم تغييره إلى Erigena وتعنى مواطن من ايرلندا.

See: William Turnner, John Scotus Eriugena, Catholic Encyclopedia,

Edited by Kevin Knight, New Advent,2012,p1.

2- يوسف كرم، تاريخ الفلسفة الأوربية فى العصر الوسيط، الفلسفة الأوربية فى العصر الوسيط،

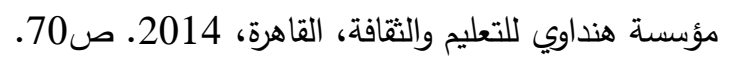




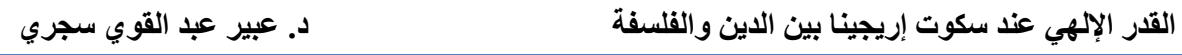
مجلة وادى النيل للاراسات والبحوث الإنسانية والاجتماعية والتربوية

فى عصر النهضـة الإيطالية، من حيث التأكيد على الحريـة والتخيل وحيويـة الفكر، وهذا ما يجعل إريجينا ليس مجرد فيلسوف من العصور المظلمة3. والحقيقـة أن إريجينـا لـم يكـن كسـائر المتقـدمين عليـه، مجـرد مصـنف وجـامع منتخبات، بل كان يملك من قوة الفكر والاستقلالية القدر الكافى لاستخدام مصـادره

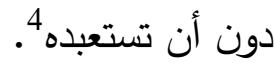
ويثمن بعض الباحثين ما لفلسفة إريجينا من طبيعة خاصة ومنفردة، أسهمت إلى حد بعيد فى تعديل العديد من المفاهيم والمقولات الواردة فى كتابات السابقين عليه فى

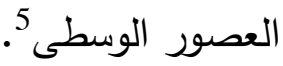

ولقد كثفت عبقريـة إريجينـا من خـلال إتقانـه للعديــ من المرجعيات، العلمانيـة

والمسيحية على حد سواء، وهذا إنجاز يمكن مضاهاته بما لتوما الإكوينى من موهبة مماثلة، من حيث معرفته الواسعة باليونانية واللاتينية، واليهودية والعربية6. وتعد مشكلة القدر الإلهى Predestination من أولى المشكلات التى وجد إريجينـا نفسـه مطالبًا أن يجد حـلًا لها، وتتبلور هذه المشكلة فهى تأكيد وجود القدر الإلهى مع الإقرار - فى الوقت نفسه- بحرية الإرادة الإنسانية. بدأت هذه المشكلة مـع

${ }^{2-}$ see: Dermot Moran,Wandering from the pass:Navigatio in the philosophy of John Scottus Eriugena,The crane Bag, The other Ireland (1976), Published by: Richard Kearney,Jastor, 2017, Vol 2, No 112, pp96-102.

4- اميل برهييـه، تاريخ الفلسفة، العصر الوسيط والنهضـة، ج 3، دار الطليعة للطباعـة والنشر ،

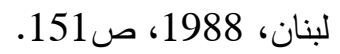

5- كوبلستون، تاريخ الفلسفة، (من أوغسطين إلى دانز سكوت)، م 2، قسم 1، ترجمة إمام عبد الفتاح وإسحاق عبيد، مراجعة وتقديم إمام عبد الفتاح، المركز القومى للترجمة، القاهرة، 2010، ص160.

6_ Deirdre Carabine, John Scottus Eriugena, Great Medieval Thinker, Oxfore uni; press, New york, 2000, p20. 
مجلة وادي النيل للاراسات والبحوث الإنساتية والاجتماعية ـ مجلة علمية محكمة

(ISSN : 2536 - 9555)

الخـاف الذى نشب بين راهب يدعى جوتشالك Gottschalk وبين كبير الأساقفة آنـالك ويـدعى هنكمـار Himcmar. فلقد أخذ الراهـب بمبـدأ الجبـر ، بينمـا رئيس الأساقفة كان يقول بمبدأ حريـة الإرادة7، وتصـاعدت المشكلة فى الكنيسة مع ما قدم جوتثالك من آراء مستخدمًا كتابات أوغسطين المناهضة للبلاجيوسية8* ووفقًا لوجهـة نظـر جوتشـالك فثــة نوعـان مـن القـدر الإلهـى : أولهمـا: قـدر المختارين للحياة الآبديـة. والآخر : قدر الأشرار الآثمين الذين لهم العقاب الأبدى. ويقول إريجينا موضحًا موقف جوتثالك: "... فإن الجنس البشري ينقسم إلى الخير والثـرير ... ونهايـة الثـرير هـى العقـاب الأبـدى، بينمـا بالنسـبة للخيـر تكـون الحيـاة

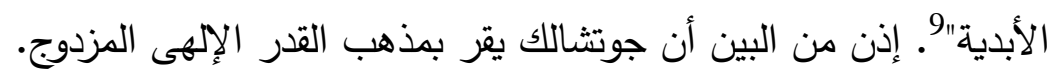

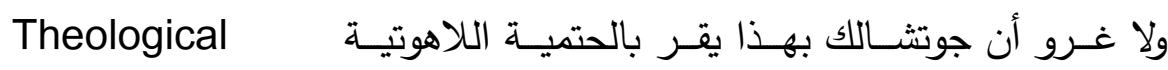
Determinis 7- راسل، تاريخ الفلسفة الغربية، الكتاب الثانى، الفلسفة الكاثوليكية، ترجمة زكى نجيب محمود،

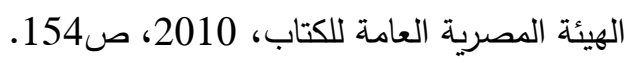

8- See: Wayne Hankey and Lloyd D P.Gerson, John Scottus Eriugena, The Cambridge History of Philosophy in Late Antiquity, vol ii, Cambridge university press,2010, p831.

* بلاجيوس رجل دين من إقليم ويلز فى انجلترا، رفض فكرة الخطيئة الأولى ورأى أن الإنسان

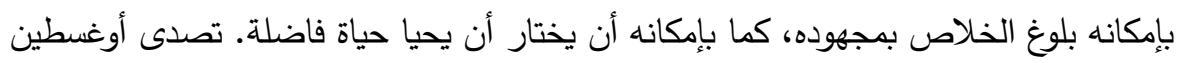
لأراء البلاجيوسية حتى أعلن كونها هرطقة.

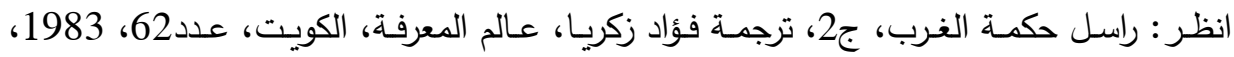
ص200.

9- John Scottus Eriugena, Treatise On Divine Predestination,trans; by Mary Brennan,Notre Dame Texts in medieval culturs,vol 5,John Van Engen editor,the medieval institute,university of notre dame press,Indiana,2002,p10. 
نظره هذه تجعل الله مسئولًا عن الشر الموجود فى العالم 10، ولقد قدم جوتثالك قضيته بأسلوب نحوي دقيق فى اللاهوت، كمـا قدمها بشجاعة وقوة. وبـلا شك هـى تهى تقدم تفسيرًا عقلانيًا قابلًا للتطبيق لموقف أوغسطين 11 بـ والنتيجة المترتبة على موقف جوتثالك هذا، أن استقامة المعتقد وصـلاح الأفعال لا جدوى منهمـا12. وسـرعان ما تحرك آباء الكنيسـة رافضـين موقف جوتشـالك، فتم تكليف إريجينا للحض ما ذهب إليه هذا الراهب الساكسونى 13، وتمت إدانته وحكم عليه بالزندقة، وعزل فى أحد الأديرة حتى لا تتتشر آراؤه الخطيرة14*.

تكمن إشكالية هذه الدراسـة فى محاولة التعرف على ماهية موقف إريجينا من

مشكلة القدر الإلهى، ومدى أصالة هذا الموقف وذلك على غرار ما قدمه من آراء

${ }^{10}$-see: Agnieszka Kijewska,Eriugena s De praedestinatione: The project of rationalization of faith and its critics,Roczniki Filozoficzne, Tom LXV, number 3,2017, P73.

11- Dermot Moran, The Philosophy of John Scottus Eriugena, (Astudy of idealism in the Middle ages) Cambridge university press, 1990, P30. 12- انظر : اميل برهييه، سبق ذكره، ص30.

13- Dermot Moran, Eriugena, Johannes Scottus, in E.Craig(ed), Routledge Encyclopedia of philosophy,London,2012,p1.

14_Agnieszka Kijewska, op.cit, p72. * - يثير إريجينا إلى كون ما ذهب إليه جوتثالك هو بدعة تتوسط الطريق بين هرطقة بيلاجيوس

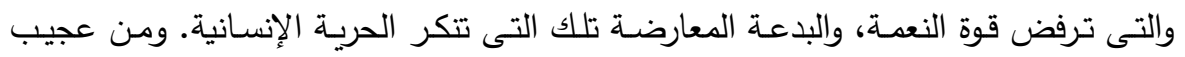

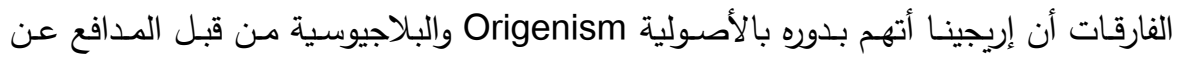

$$
\text { جوتثالك، المطران "برودينتيوس أوف تروى" Prudentius of Troy. }
$$

See: Dermot Moran, John Scottus Eriugena, Standford Encyclopedia of Philosophy, Standford univ; Copyrights by Metaphysics Research lab, 2016,P5. 
تخص اللاهوت والطبيعة. وسوف نحاول إماطـة اللثام عن موقفه من قضية القدر الإلهى من خلال محاولة الإجابة عن التساؤلات التالية: - أولًا: كيف تتاول إريجينـا مشكلة القدر الإلهى، هل عول على العقيدة والكتاب الإله المقدس لعرض وجهـة نظرة؟ أم ركن إلى الفلسـفة والجدل إيمانًا منـهـ بقوتههـا

$$
\text { وكفايتهما للدلالة على موقفه؟ }
$$

- ثانيًا: هل استطاع إريجينا التوفيق بين القول بالقدر الإلهى والحرية الإنسانية؟

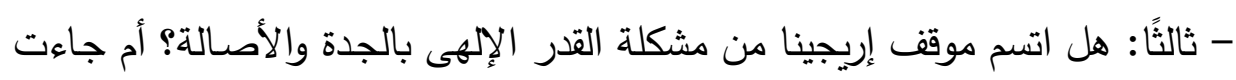
معالجته لها إعادةً وتكرارًا لموقف سابقيه؟

$$
\text { هذا ما سنحاول الكثف عنه فيما يلى. }
$$

المنهه: ولعل أكثر المناهج ملاعمة لمعالجة موضوع الدراسة هو المنهج التحليلى

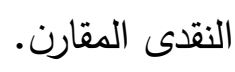

وسوف نتناول موضوع الاراسة من خلال العناصر التالية:

أولاً: تصور إريجينا للات الإلهية:

$$
\text { 2- 1 - أنماط الوجودة والجوهر الإلهي. }
$$

ثانيًا: مكانة الفلسفة والجدل عند إريجينا.

$$
\text { 1- أهمية الفلسفة. }
$$

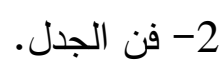

ثالثًا: مشكلة القدر الإلهى: الجد:

1- الإختيار الحر للإرادة الفردية مصدر الخطيئة.

$$
\text { 2- تعريف القدر الإلهى. }
$$

3- اعتماد إريجينا على الفلسفة والجدل لإثبات عدم ازدواجية القدر الإلهى.

$$
\text { 4- القدر الإلهى والعلم الإلهى المسبق. }
$$




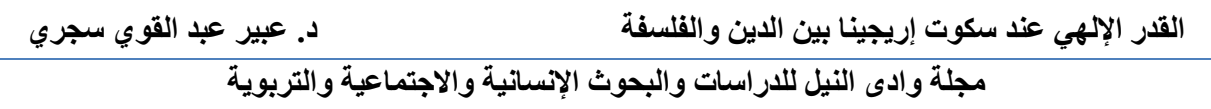

ولكن قبل الشروع فحى لابد من التعرف على الملامـح العامـة لمكانـة إريجينـا

الفكريـة فى عصره، فما هى؟

لا غرو أن حياة إريجينا لم يعرف عنها سوى القليل، باستثناء الفترة التى إلتحق

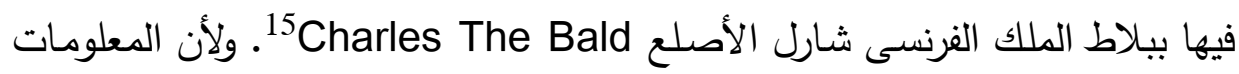

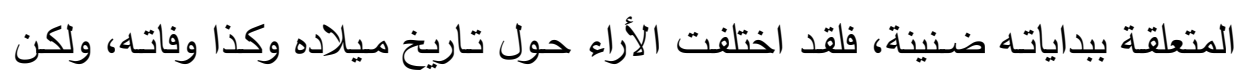

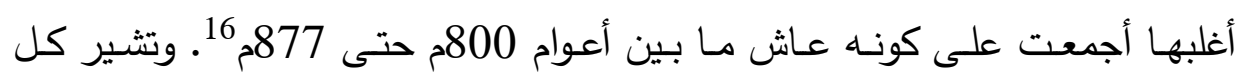

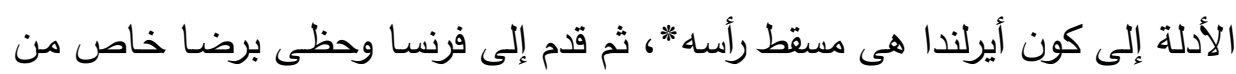

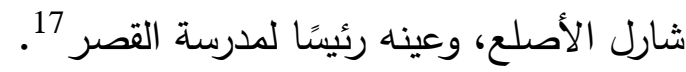
ولقد عرفت هذه الفترة بعصـر النهضـة الكارولنجيـة*** ، إذ بعد تولى شـارلمان

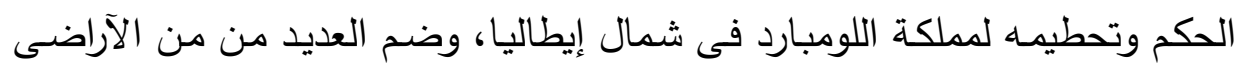
المتاخمـة لملكه؛ اهتم برفع المستوى الثقافى لرعاياه فى مجال التربية والتعليم بصفة

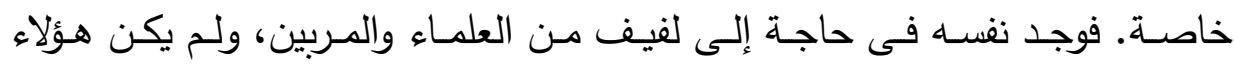
متوفرين فى مملكة الفرنجة، فاستقدمه من مختلف بلدان أوربا 18.

16 - 15- راسل، حكمة الغرب، سبق ذكره، ص219.

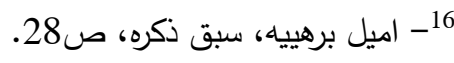

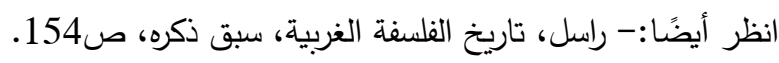
- راسل، حكمة الغرب، سبق ذكره، ص219.

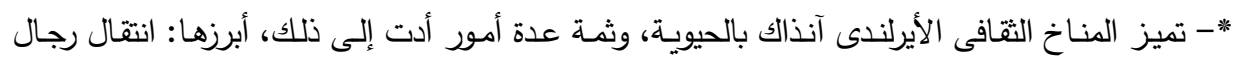

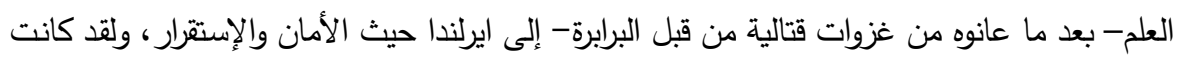

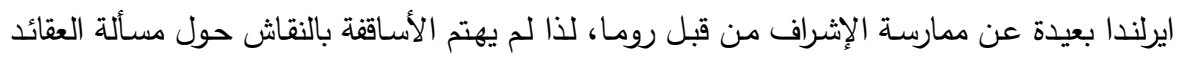

الجامدة، مما وفر لهم مناخ التحرر، وانعكس على إريجينا.

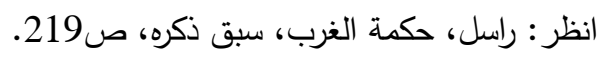

17 - William Turnner,Op.cit,p1.

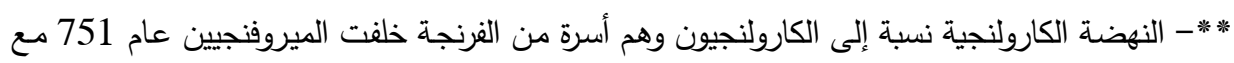

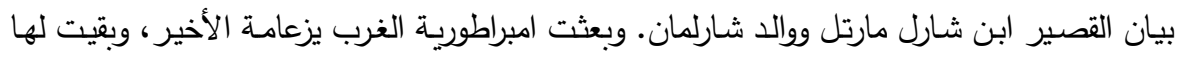
السيادة فى فرنسا حتى عام 911، وفى جرمانيا حتى عام 987. 
ومن بين المواد التى كانت يهتم بتدريسها فى هذه الفترة الجدل، والذى كان يمثل الفلسفة، وكان مقصورًا آنذاك على كتب آرسطو المنطقية الثلاثة: المقولات والعبارة والتحليلات الأولى. على أن مسائل فلسفية كثيرة كانت تعالج فى مناقثات لاهوتية، وكانوا يعولون على آباء الكنيسة وبالأخص أوغسطين 19.

وبرغم ذلك يذهب كوبلستون إلى كون القرن التاسع قد شهد نشاطًا تعليميًا متدنى لـى

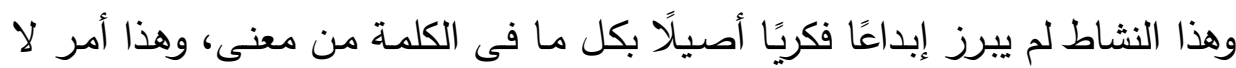
غرابة فيه، إذ اتسم العصر بمجادلة الحفاظ على ما هو قائم وتطويره قدر الإمكان. وأن المنظومة التى قدمها إريجينا من أهم علامات القرن التاسع الميلادى فى أوربـا الغربية، فهى بمنزلة صخرة شامخة وسط سهل عريض ساكن النه 20.

\section{أما مؤلفاته فيمكن تصنيفها إلى:}

1 - كتابـات لاهوتيـة: وتتمثل فى رسالته حول القدر الإلهى * Predestination وهى أول مصنفاته وجاءت بناء على طلب أسقفين للرد على أحد الرهبان، قال فيها بمبدأ الجبر الإلهى فطلبا من إريجينا الرد عليه 21. 2- الترجمات والتعليقات: وجاءت نتيجة لمعرفة إريجينا الجيدة باللغة اليونانية22، ولقد ترجم أعمال ديونسيوس Pseudo-Dionysi، مثل "الأسماء الإلهيـة"،

$$
\begin{aligned}
& \text { انظر : اميل برهييه، سبق ذكره، هامش ص7. } \\
& \text { 18- كوبلستون، سبق ذكره، ص151 : 151. } \\
& \text { 19- يوسف كرم، سبق ذكره، } 69 . \\
& \text { 20- كوبلستون، سبق ذكره، ص159. }
\end{aligned}
$$

*- تجدر بنا الإثارة إلى أن أغلب المؤلفات العربية، بل والمترجمة عن اللغة الإنجليزية قد تعاملت

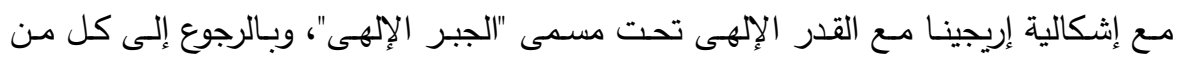
الترجمـة العربية للمصطلح Predestination فى القواميس، وكذلك إلى نصـوص إريجينـا،

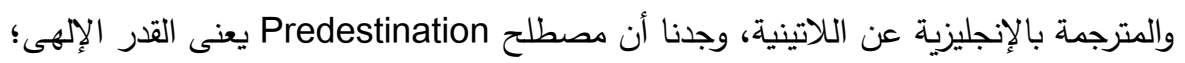

$$
\text { لذا وجب التنويه. }
$$

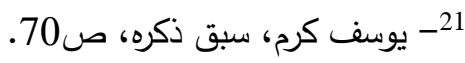




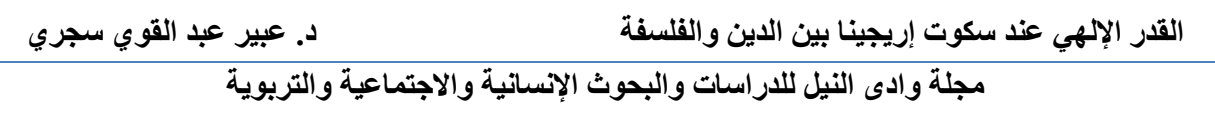

و"التسلسـل الهرمسى"، "واللاهـوت الصـوفى "23، كمـا ترجم وعلق على أعمـال ماكسيموس المعترف Maximus Confessor ولقد منحته هذه الترجمات معرفـة أكثر قربًا بفكر آبـاء الكنيسـة الثـرقيين 24. كمـا ترجم كتاب القديس جريجورى أوف نيسا Gregory of Nyssa وعنوانه "خلق البشر". وعلق

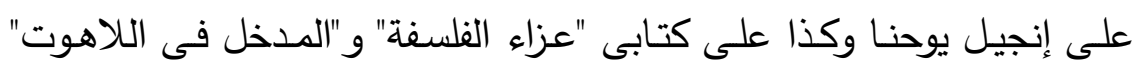
لبؤثيوس

3- القصائد: ولإريجينا العديد من القصائد، كتب بعضها باللاتينية وبعضها الآخر

$$
\text { باليونانية }
$$

4- كتابات فلسفية: يعد مؤلف "أقسام الطبيعة" Periphseon أهم إضـافة فكريـة لإريجينا، وتم وضـع هذا الكتاب ما بين أعوام (862-866) بمنزلة نموذجٍ للتفنير المبسط لكيفية النظر إلى العالم المادى الإلهى، بوصفه مكانًا يملؤه مفهوم الطاقات الطبيعية الإلهية28، وهو عبارة عن حوار بين أستاذ وتلميذه ويقع فى خمسة كتب 29، يتحدث فى الكتاب الأول عن الله، بينما فى

\footnotetext{
22- William Turnner,Op.cit,,p1.
}

23- Dermot Moran,Eriugena,John Scottus,Medieval Science, Technology And Medicine,An Encycolopedia,Thomas Glick,Steven. J.Livesey, Faith Wallis,Editors Research Gate,2005,P162.

24- Ibid,P162.

$$
\text { 25 - كوبلستون، سبق ذكره، ص161. }
$$

26_ William Turnner,Op.cit,p1.

$$
\text { 27 - كوبلستون، سبق ذكره، ص162. }
$$

28- See: lise.A.schweitzer, Strange, Beauty: Ecocritical Approaches to early medieval landscape, by Alfred.K.Siewers, Review,oxford uni; Jastor, 2017, P237.

29_ Dermot Moran, John Scottus Eriugena, Standford Encyclopedia of Philosophy,P10. 
مجلة وادي النيل للاراسات والبحوث الإنسانية والاجتماعية - مجلة علمية محكمة

(ISSN : 2536 - 9555)

الكتابين الثانى والثالث؛ يتناول القسمين الثانى والثالث للطبيعة، أما الكتابين

الرابع والخامس فيدوران حول عودة الخلق إلى مصدره الإلهى

\section{أولاً: تصهر إريجينا للذات الإهية}

فى الحقيقة لم نجد فى طيات كتاب إريجينـا "رسالة حول القدر الإلهى" فكرة

متكاملة عن تصور إريجينا لطبيعة الذات الإلهية. حيث صساغ هذه الفكرة بالتفصيل

فيما بعد فى كتابه "أقسام الطبيعة". ويمكن الجزم بضرورة عرض تصوره عن الله كما جاء فى كتاب "أقسام الطبيعة"، للوقوف على الكيفية التى فهم بها إريجينا الجوهر الإلهى، وذلك لاستيعاب منهجه فى التعامل مع مشكلة القدر الإلهى.

1- معرفة الجهوهر الإهىى:

يلاحظ إريجينـا أن الجوهر أبعد مـن أن يعـرف وأنـه وجـود متعـالٍ 31، ولا يعلـم

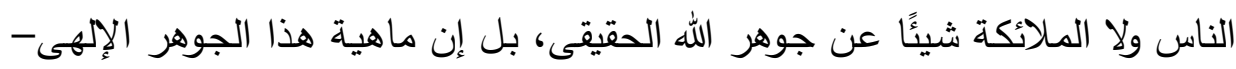

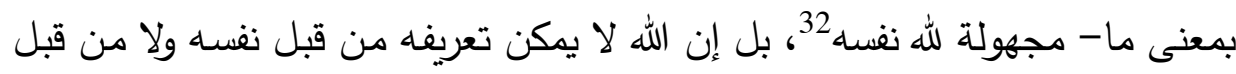

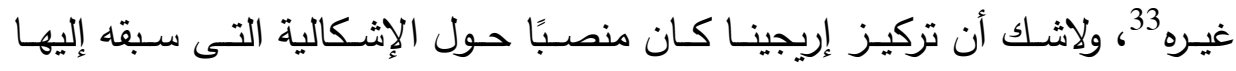
ديونسيوس المنحول Dionysius The Areopagite، التى تتمحور حول الكيفية

30- Darren Hibbs,Eriugena,Berkeley,and Hegel:The variety of idealism in The western philosophical tradition,PH.D,univ; of Arkansas, 2001, p107.

31- David C.Puxly, Soul as self and mediator from Plotinus to Eriugena, M.A, Dalhoosie Univ Canada, 2005, P115.

32 - راسل، تاريخ الفلسفة الغربية، سبق ذكره، ص157.

33 - see: Iohannis Scotti Erivgenae, Periphyseon edited by I.P.SheldonWilliam, The Dublin Institute for Advanced Studies, Dublin, 1972, B2, 28, p139. 


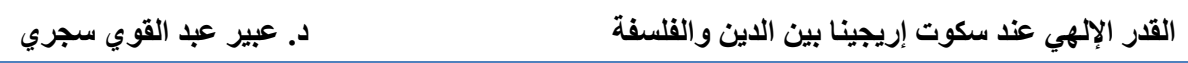

$$
\begin{aligned}
& \text { مجلة وادى النيل للاراسات والبحوث الإنسانية والاجتماعية والتربوية }
\end{aligned}
$$

التى يمكن من خلالها إدرالك الجوهر الإلهى غير المفهوم فى حد ذاته، والتعبير عنه من خلال تجلياته فى الخلق 34.

ولقد أخذ إريجينا عن الأفلاطونية المحدثة كون الله هو المبدأ الذى انبثقت منـه

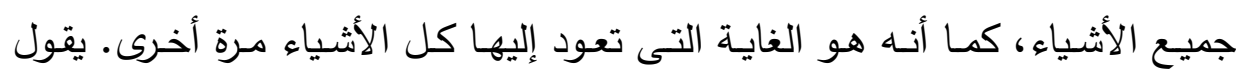
إريجينا: "...هو مبدأ كل الأشياء التى خلقها، كما أنه النهاية التى تبحث التهاء عنها جميع

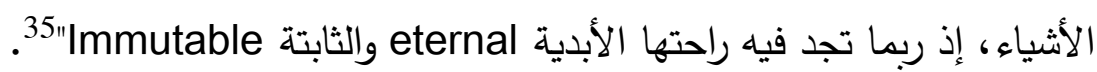

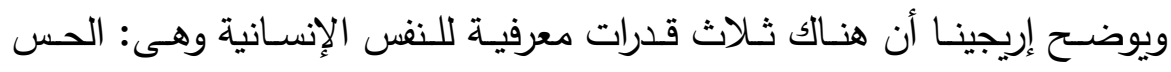
الداخلى Inner sense، والعقل Reason، والفكر Intellect ومن ثم فإن معرفة الله ثلاثية. أولها: معرفة الله من خلال الإيمان البسيط به وذلك من خلال الكتاب المقدس. ثانيها: معرفة الله بواسطة العقل عن طريق تجلياته فى العالم المادى. ثالثها: معرفة الله من خلال الفكر ، أى من خلال ما يستقر فى الوجد36. وبعد جدال كبير، وصل وصل إريجينا

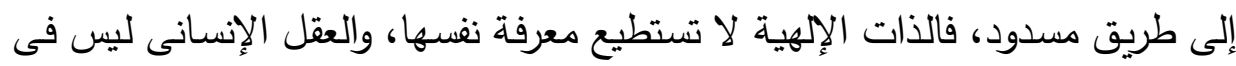

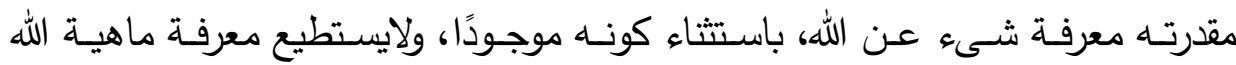
بوصفه الجوهر المكون للأشياء فى الخلق من 37.

Negative وهكا وجد إريجينا الحل فى السلب، أى باستخدام اللاهوت السلبى Theology الله المتعالية فوق الخلق؛ فاللاهوت السلبى بهذا يكون محاولة وصف وتأمل للطبيعة

34- Deirdre Carabine, The unknown God,Negative Theology in Platonic Tradition: Plato to Eriugena,Peeiers press,Louvain,1995,P306.

35- Iohannis Scotti Erivgenae, Periphyseon, op.cit, B2,2,p9.

36- See: Julio Burunat, Faith and Reason in The thought of John scottus Eriugena, PHD Fordham university, NewYork, 1984, P89.

37 - Deirdre Carabine, The unknown God,op.cit,P317. 
مجلة وادي النيل للاراسات والبحوث الإنساتية والاجتماعية ـ مجلة علمية محكمة

(ISSN : 2536 - 9555)

الإلهية من خـلال إنكار كل الصفات الإلهية التقليدية38. ووفقًا ل Otten، فلقد مثل اللاهوت السلبى أداة مفيدة لإريجينا مكنته من توسيع نطاق إدراك العقل الإنسانى،

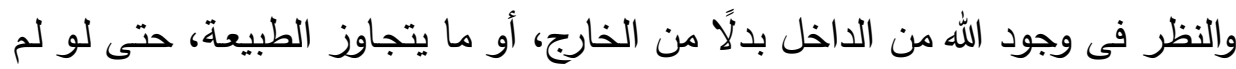
يتم التوصل لنظرة كاملة لمفهوم الألوهية

Affirmative Theology وقد يبدو أن ثـة تعرض بين اللاهوت الايجابى واللاهـوت السـلبى، ولكن إريجينـا يقرأنـهـ لا تعـارض بـين كـل مـن نـوعى اللاهـوت الإيجابى والسلبى، وذلك عند تطبيقهما على الذات الإلهية. يقول إريجينا: "...عندما نصل لوجهة نظر من التعقل التام، سوف نرى بوضوح كافى أن هذين الاثنين، قد

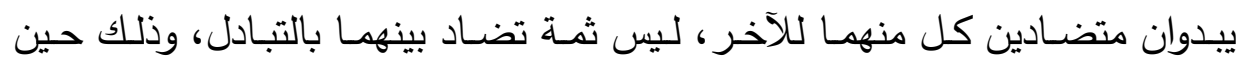
يطبقون على الطبيعة الإلهية، ولكن نجدهما منسجمين مع بعضهما بعضًا وذلك بكل السبل وفى كل نقطة فيهما"40.

ولقد مـزج إريجينا بين مختلف العناصـر الفلسفية، فى لاهوته السلبى، حيث

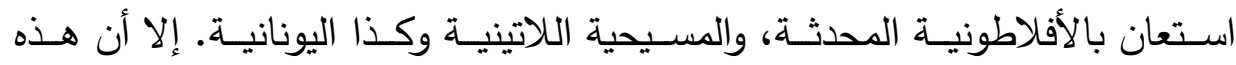

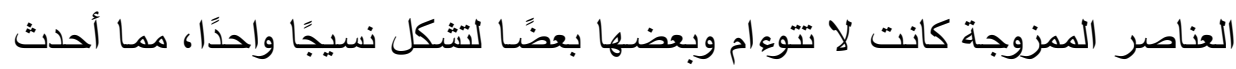

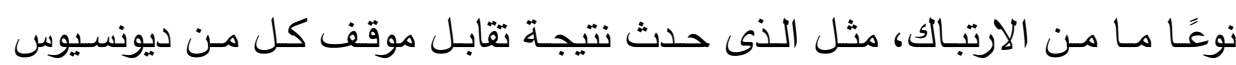

38- See: Willemien Otten, The Anthropology of Johannes Scottus Eriugena, E.J.Brill, Leiden, NewYork, 1991,P48.

39- Willemien Otten, Nature Religious Force in Eriugena, Emerson, Fordham uni; press, NewYork, 2008, P357.

Margaret P.Twomey, Towards enhanced divine- human-earth relation:

Achristian- Buddhist contribution, PHD, university college cork, Ireland, 2014, P92.

40_ Iohannis Scotti Erivgenae,Periphyseon,edited by I.P.SheldonWilliam, The Dublin Institute for Advanced Studies,Dublin,1968, B1,P81. 


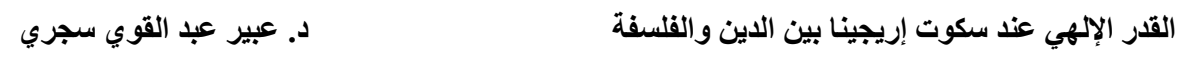
مجلة وادى النيل للاراسات والبحوث الإنسانية والاجتماعية والتربوية

وأوغسطين إزاء تلك المسألة 41. ولاشك أن التأثير الأكبر لتمييز إريجينا بين نوعى اللاهوت الإيجابى والسلبى، كان لديونسيوس، فإن اللاهوت السلبى عند إريجيناوالموجود فى كتابه "أقسام الطبيعة"- يشكل توسعًا لنطاق حدود علم اللاهوت السلبى

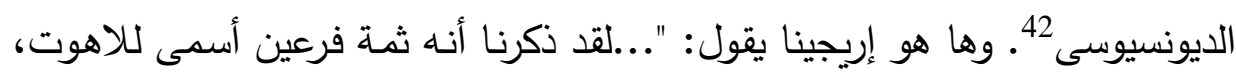
وأن هذا لم نقله بأنفسنا، بل بالمرجعية إلى القديس ديونسيوس المنحول، والذى جزم بجلاء كون علم اللاهوت ينقسم إلى جزءين"43 والسؤال الآن، ترى ما هـى أهم ملامح اللاهوت السلبى عند ديونسيوس؟ بداية لقد كان نهج ديونسيوس فى التعامل مع مسألة اللاهوت مخالفًا لنهج آباء الكنيسـة السـائد آنذالك. برغم أن أباء الكنيسـة كانوا يبدأون بالاهلاهوت السلبى لتأكيد اللاهوت الإيجابى، نجد ديونسيوس يرى فى اللاهوت الإيجابى تمهيدًا لمعرفة الله عن طريق اللاهوت السلبى، إذ إن إيجـاب الصـفات للمخلوقات يـدل على عدم لياقتها لوصف الذات الإلهية؛ لذا وجب سلبها عنها؛ وبالتالى فالمعرفة السلبية أصدق تعبيرًا، ولائقة بالذات الإلهية44.

ويرى ديونسيوس أنه من الواجب علينا إثبات كل صفات الأشياء الموجودة للذات الإلهية وتأكيدها، ولكن الأكثر ملاعمة أن ننفى جميع هذه الصفات عنه، لأنه يعلو

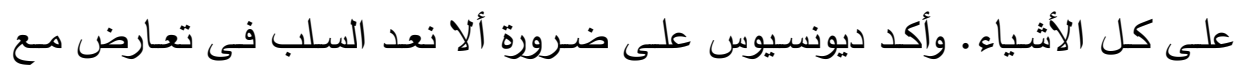

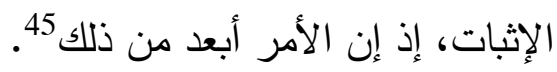

40- See: Deirdre Carabine, The unknow God,Op.cit,P302.

41- Ibid, P321.

43- Iohannis Scotti Erivgenae, Periphyseon, op.cit, B1,P81.

$$
\text { 44 يوسف كرم، سبق ذكره، ص57. }
$$

45-See:Dionysius The Areopagite, Dionysius The Areopagite Works (1897), Mystic Theology, Caput 1, section 2, Trans by John Parker, Grand Rapids, Mi:Christian Classics Ethereal Library, London, 1897, Date Created: 2005, p68. 
إذن يرى ديونسيوس أن ثـة لاهوتًا إيجابيًا يعبر عن الذات الإلهية، كأن نقول أن الله هو الحق والخير والجوهر وغيرها من الصفات التى لا يمكن إطلاقها إلا على

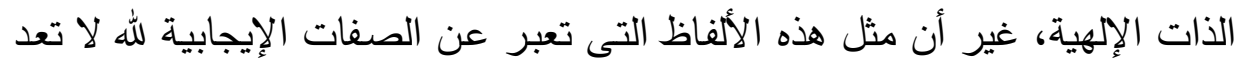

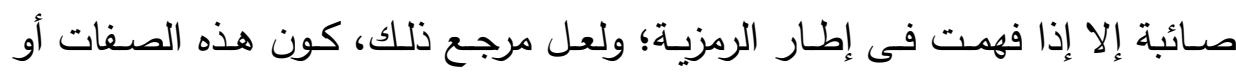

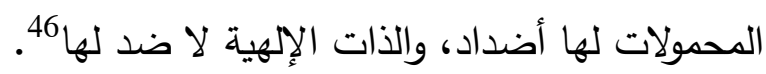
ولقد اتبع إريجينـا مـا ذهـب إليـه ديونسيوس مـن كون الحفـاظ على الدلالات

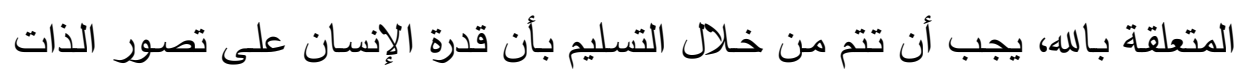
الإلهية تعجز عن أى حمل على الذات المتعالية المطلقة؛ وبالتالى يجب أن يكون

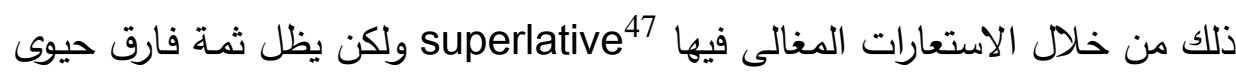
ومدهش بين اللاهوت السلبى عند كل من ديونسيوس وإريجينـا، فلاهوت إريجينا يكافح بلا هوادة لتطهير نفسه وتصوراته عن الله بغية الوصول إلى الوحدة مـع الذات الإلكهية 48. أمـا فيما يتعلق بمعرفة الله من خـلال تجلياته ومخلوقاته، بداية لابـد من التأكيد

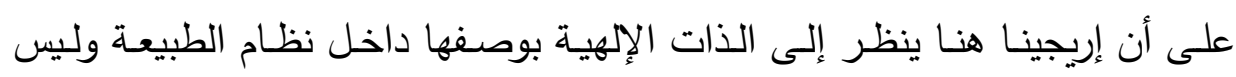

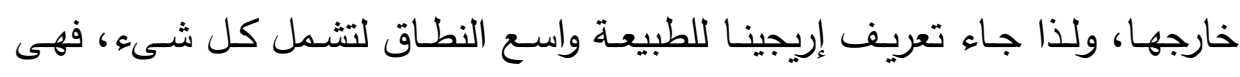
"مجموع كل الأثياء" بما فى ذلك الموجود منها Being وغير الموجود على حد سواء، الله والخلق 49، يقول إريجينا: "إذن الطبيعة هـى اسم عام، كم ذكرنا، لكل الأشياء، تلك الموجودة والتي لا وجود لها" لـاءل.

46- ـ راسل، تاريخ الفلسفة الغربية، سبق ذكره، ص157.

47- David C.Puxly, op.cit,P115.

48- Deirdre Carabine, The unknow God,P321.

49- Dermot Moran, Eriugena,John Scottus,Medieval Science, Technology And Medicine,op.cit,P162.

50_ Iohannis Scotti Erivgenae, Periphyseon,op.cit,B1,P37. 
القدر الالهي عند سكوت إريجينا بين الدين والفلسفة

إذن لقد رأى إريجينا أن خير سبيل للتعبير عن الذات الإلهية المتعالية وغير المعروفة حتى لذاتها ،يكون من خلال اللاهوت السلبى وحده.

2- أنماط الوجود واللاوجود:

لقد ناقش إريجينا مسألة أنماط الوجود واللاوجود الخمسة فى صفحات قليلة من كتابـه "أقسام الطبيعـة" لكى يركز على فكرة أن عدم معرفـة الحقيقـة هـ فـى ذاته معرفة51. وهذه الأنماط وإن لم تكن شاملة إلا أن جميعها تتطبق على الطبيعة 52. ويتـاول هذه الأنماط على النحو التالى: فـى الـمط الأول يقسم الوجـود إلى

أعراض وجواهر 53. فى هذا النمط يرى إريجينا أن الثىء الذى يقنعنا بـه العقل أنه موجود، وكذا الحواس، فهذا الثـى يكون موجود فى الحقيقة 54؛ إذن يتمحور هذا

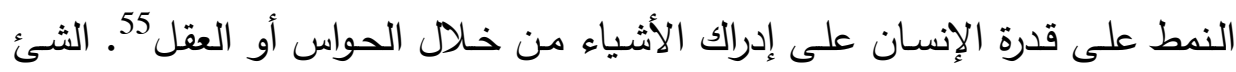
الذى يمكن إدراكه عن طريق الحواس أو العقل فهو موجود، وما يخرج عن نطاق الاق الإسن

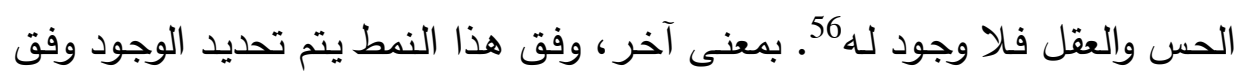
المعايير المعرفية

النمط الثانى: ينظر هنا إريجينا للموجود واللاموجود من خلال تدرج والطبائع

المخلوقة واختلافها والتى تبدأ من الطبائع العقلية والموجودة فى أعلى السلسلة بالقرب من الله وتتحدر إلى المخلوقات الأكثر بعدًا، وهى المخلوقات العاقلة وغير العاقلة $58 ،$

51-See: Deirdre Carabine,The unknow God,op.cit,P316.

${ }^{52}$-Deirdre Carabine,John Scottus Eriugena,op.cit ,p38.

53- عبد الرحمن بدوى، فلسفة العصور الوسطى، وكالة المطبوعات الكويت، دار القلم لبنان، ط3،

1979، ص51.

${ }^{54}$-see: lohannis Scotti Erivgenae,Periphyseon,op.cit ,B1,P39

55_Darren Hibbs, Eriugena,Berkeley,and Hegel,op.cit, P107.

56-Deirdre Carabine,John Scottus Eriugena,op.cit ,p38.

57 - Dermot Moran, The philosophy of John Scottus Eriugena, op.cit, P219.

58 - Iohannis Scotti Erivgenae, Periphyseon,op.cit, B1,4,P41. 
فهذا النمط يرتكز على فكرة التدرج الهرمى للكائنات فى الكون الإريجينى 59.

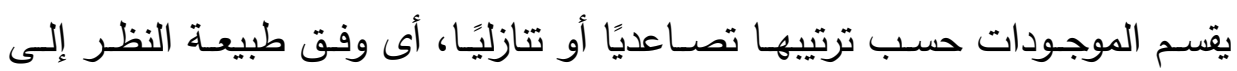
الثىء، فإذا نظر إليه من جهة ما هو أعلى منـه، فهو موجود. أما إذا نظر إليه من جهة ما هو أدنى منه، فهو غير موجود

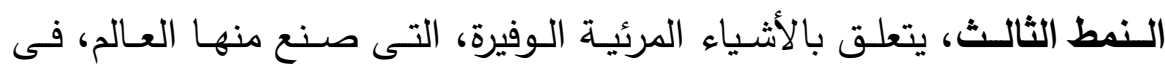

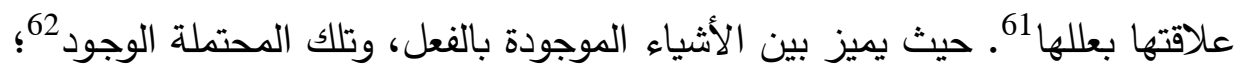
بمعنى آخر ، يميز بين الثىء إذا أصبح واضحًا فى المادة والصورة والمكان والزمان؛

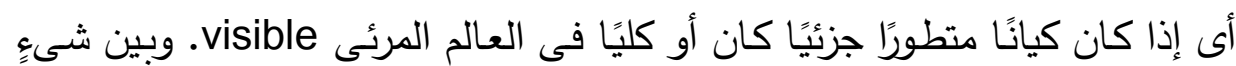
آخر يفتقر إلى الوجود، أى كيانٍ محتملٍ لم يثبت نفسه بعد فى العالم 63.

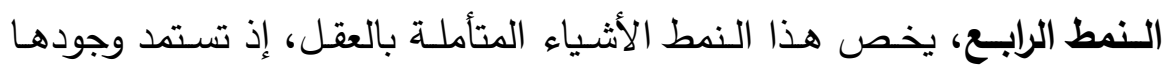

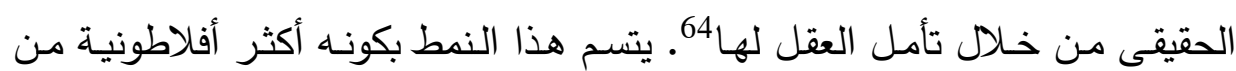
حيث الثكل form، إذ يرى أن الأشياء العقلية Intelligible وحدها هـى الموجودة

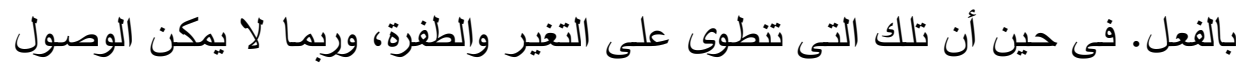
إليها إلا من خلال الحواس، ليست موجودة؛ ويترتب على ذلك أن أى جسد Body مشارك فى عملية التوالد Generation والتغير والعالم الزمنى، بهذا المعنى، ليس لله وجود

59- Darren Hibbs, Eriugena,Berkeley,and Hegel,op.cit P107.

$$
\text { 60 - عبد الرحمن بدوى، سبق ذكره، ص25. }
$$

61_ Iohannis Scotti Erivgenae,Periphyseon,op.cit ,B1,5,P43

62- Dermot Moran, The philosophy of John Scottus Eriugena ,op.cit, P223.

63 - Darren Hibbs, Eriugena,Berkeley,and Hegel,op.cit, P108.

64_ Iohannis Scotti Erivgenae,Periphyseon,op.cit ,B1,6,P45.

65- Dermot Moran, The philosophy of John Scottus Eriugena, op.cit, P224. 


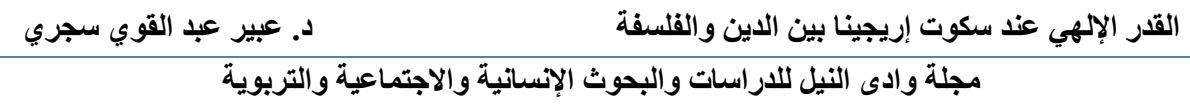

النمط الخـامس، يتعلق بالطبيعـة الإنسـانية66، فمنذ سقوطها من الجنـة، فقدت

صورتها الإلهية، وجوهرها الحقيقى؛ وبالتالى- بمعنى ما- نقول إنها غير موجودة،

وعندما تستعد الطبيعـة الإنسـانية نفـها مـن خـلال النعمـة الإلهيـة، تعود لطبيعتها

$$
\text { وتصبح موجودة }
$$

من خلال التصنيف السابق لأنماط الطبيعة حصر إريجينا كل الأشياء الموجودة

$$
\text { وغير الموجودة فى الكون كما إرتآه. }
$$

3- أقسام الطبيهمة:

يجسـ تقسيم الطبيعـة الربـاعى لإريجينـا مسـألتى النشـأة Procession والعـودة Return للطبيعة على النحو التالى:- طبيعة تخلق ولا تخلق.(الله)، وطبيعة لا تخلق وتخلق (العلل الأولى)، وطبيعـة تخلق ولا تخلق (الكائنـات الزمنيـة)، وطبيعـة لا تخلق ولا تخلق (الله) وثمة عدة ملاحظات على هذا التقسيم يمكن إجمالها فى التالى:

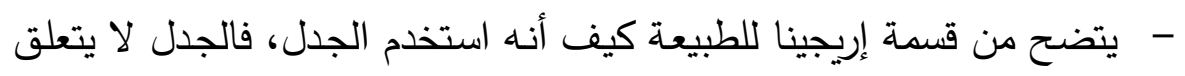
بالكلمـات أو الأفكار فقط، بـل استخدمه إريحينـا لوصف بنية الواقع.ويشير القسمان الأول والرابع إلى الله بوصفه البداية والنهاية لكل الأشياء، حيث إنها إلها بأكملها تصدر عنه وتعود إليه

66- Iohannis Scotti Erivgenae,Periphyseon,op.cit ,B1,7,P45.

67 - Deirdre Carabine,John Scottus Eriugena,opcit,p40.

68 - Darren Hibbs, Eriugena,Berkeley,and Hegel,op.cit ,P106.

$$
\text { 69- انظر : راسل، تاريخ الفلسفة الغربية، سبق ذكره، ص157. }
$$

See also: lohannis Scotti Erivgenae,PeriphyseonB1,Opcit ,P37 70 - Julio Burunat,op,cit,P113. 
مجلة وادي النيل للاراسات والبحوث الإنساتية والاجتماعية ـ مجلة علمية محكمة

(ISSN : 2536 - 9555)

- - القسمان الثانى والثالث فيعبران عن وحدة العلاقة بين السبب والنتيجة هذا التقسيم فى مجمله من قبل إريحينا، محاولة للكثف عن ماهية الطبيعة التى هى عبارة عن جدلية العلاقة بين الوجود واللاوجود ${ }^{72}$.

\section{ثانيا: هكانة الفلسفة والجدل عند إريمينا}

1- أهميسية الفلسفة:

تجدر الإشارة إلى كون إريجينا لم يفرق بين الدين والفلسفة، إذ أن كليهما صـادر

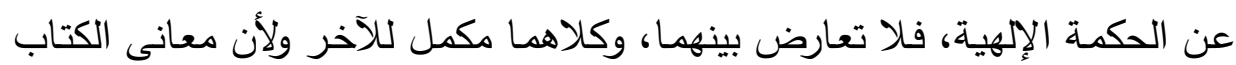
المقدس متعددة، فيمكننا- من خلال استخدام العقل- اختيار المعنى الأكثر ملاءمة، بل يتعدى الأمر ذلك فبإمكاننا تأويل ما ورد فى الكتاب المقدس 73. بل نجد إريجينا يتعامل مع الدين والفلسفة بوصفهما وجهين لعملة واحدة، وهذا يتضـح من نص كلام إريجينـا إذ يقول: "...يترتب على ذلك أن الفلسفة الحقيقيـة هـى العقيدة الحقيقيـة، والعكس، العقيدة الحقيقية هى الفلسفة الحقيقية"74. إن فكرة إريجينـا عـن الإنسـان بوصـفه صـورة لله أدت مباشـرة إلى تأييـد القـوة المطلقة للعقل الإنسانى 75.

ومـن الغريـب أن إريجينـا قد أدرك أن رحلتهـ فى العقل سـؤدى بـه إلى المنفى الكنسى، وأن رحلته هذه سوف تحيد عن المسار النموذجى، ولكن إريجينا آثر الثراء

71_ Dermot Moran, John Scottus Eriugena, Standford Encyclopedia of Philosophy,Op.cit,p10

${ }^{72}$-see: Deirdre Carabine, John Scottus Eriugena,op.cit,p30.

73- انظر يوسف كرم، سبق ذكره، ص71.

74_ John Scottus Eriugena, Treatise On Divine Predestination,op.cit,p7

75 - Dermot Moran,Wandering from the pass,op.cit,P98. 


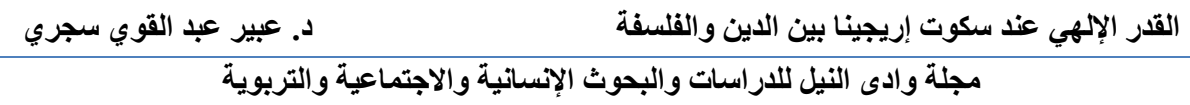

والقوة والحقيقة فى هذه التجربة، ومن الممكن أن هذه الأشياء مثلت حافزًا للفيلسوف

الأيرلندى للطعن على الواقع القائم 76.

ولقد زعم إريجينـا أنـه لا يمكن لأحد دخول الجنـة إلا بالفلسفة، وأن الفلسفة أو لون

السعى وراء الحكمة ليس مخالفًا للدين؛ وذلك لأنها - كما سبق وذكرنا- الفلسفة هى رهى

الدين الحقيقى، والعكس، الدين الصحيح هو الفلسفة الحقيقية. كما أنها لم يفرق بين

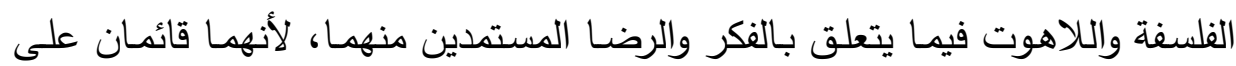
كل مصـادر الحقيقـة المتاحـة لـه، بمـا فـى ذلك الكتاب المقدس والأدب المسيحى المبكر

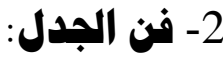

لقد كان التعليم فى القرن التاسع الميلادى فى ثلاث درجات: - تعليم الدرجـة الأولى كان إزامًا للمرشحين للكهنوت ومفتوحًا للمدنيين. وأهـم مواده القراءة والكتابة ومبادئ اللاتينية الدراجة وشرح الكتب الدينية. - تعليم الدرجة الثانية وهو تعليم الفنون الحرة السبعة، وتكون على مجموعتين: مجموعة ثلاثية: تتكون من الجراماطيقا والخطابة والجدل (وكان يمثل الفلسفة). ومجموعة رباعية: تتكون من العلوم السابقة بالإضافة إلى الطب.

سميت علوم المجموعة الثلاثية بالعلوم العقلية، وسميت علوم المجموعة الرباعية بالعلوم الوجودية حيث تتاولت حقائق مستقلة عن العقل. - تعليم الدرجة الثالثة وهو يختص بتعليم الكتب المقدسة، ولقد جاء ترتيبها متأخرًا،

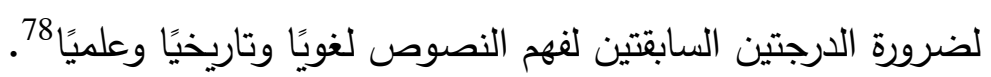

76_ lbid, P99.

77- James Mcevoy, Happiness in the intellectual life, The Cambridge companion to Medieval philosophy,edited by A.S.McGrande,P266.

78- يوسف كرم، سبق ذكره، ص68. 
مجلة وادي النيل للاراسات والبحوث الإنساتية والاجتماعية ـ مجلة علمية محكمة

(ISSN : 2536 - 9555)

وكما سبق وآشرنا فلقد كان إريجينا مهتمًا بإصلاح المعايير التعليمية فى عصره،

وذلك من خـلال تقديم مفهوم محدد للمعرفة، أو بشكل أكثر دقة، مفهوم محدد عن الفلسفة. ولقد كان جزءًا أساسيًا من هذا الإصـلاح، هو إعادة التأكيد على ما تلعبه

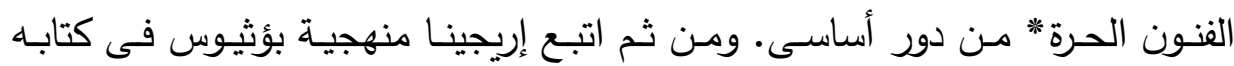
الثالوث De trinitate لم يضـع كاتب فى زمنـه مثل هذا التأكيد الهائل على دور هذه الفنون للفلسفة، بل

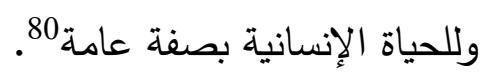

ولقد حـاول إريجينـا الجمـع بـين المفهوم التقليدى الغربى اللاتينى للجدل، مـع

الديالكتيك السلبى اليونانى الأفلاطونى، لإيجاد فهم جديد للجدل الذى يشبه أسلوب المثاليين المتأخرين. والفهم اللاتينى للجدل، الذى ينبع من شيشرون وبؤثيوس، يمثل التيل تفسيرًا لجدل أرسطو، الذى كان يراه بوصفه حججًا منظمة تتصارع فيما بينها. وجدل أرسطو يتعامل مـع الممكن Probable أو المعتقد Believable، بوصفيه مقابـل يراه لليقين Certain. والجدل بهذه الصورة لا يقدم حججًا مستمدة من المبادئ الثابتة، أما الكـارولينجيين، فقد كان اتجـاههم هو الحفـاظ على عدم إمكانيـة إضـافة أى جديد للفلسفة، حيث إنها تحتوى على الفنون مكتملة، التى تمثل فى ذاتها نمـاذج كاملة للمعرفة، وهى ثابتة ولا يمكن تغييرها بأى شكل من الأشكال. ولقد اتبع الكارولينجيين

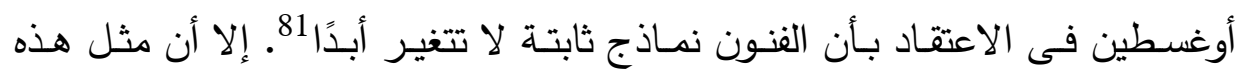

*- أثار إريجينا إلى الأخطاء التى وقع فيها جوتثالك إزاء مشكلة القدر الإلهى جاءت نبعت من

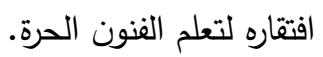

-Jhon Chistian Macinnis, The Harmony of all things: Music, Sool, and

Cosmos in The writing of, Florida state univ; PHD, 2014, P19.

79-See: Agnieszka Kiewska,Eriugena s De praedestinatione,op.cit, P83.

80 - Dermot Moran, The Philosophy of John Scottus Eriugena,op.cit, P130.

81- Ibid,P123:129 
التصنيفات التقليديـة للفلسفة حدت بشدة من إمكانية تطوير علوم جديدة، حتى تم إحياء أرسطو، وأخيرًا حطم هذا الإطار الجامد 82.

فإن إلمسام إريجينـا بالثقافة المسيحية البيزنطيـة قـاده نحـو تطوير مفهوم جديـ الإسيد

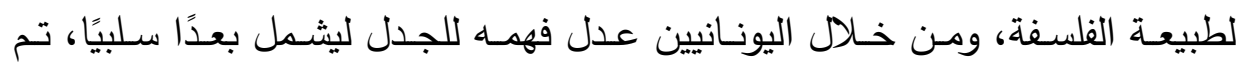
تطويره- من امتداد الأسلوب الثرقى السلبى، حيث يطبق على الله- للتطبيق على الطبيعـة البشـرية والعـالم. بـل إن مفهوم إريجينـا للجدل كـان ينطـى على إمكانيـة توضـيح النشـاط الطبيعى للعقل ذاتـ، فإن عمليـات العقل مـا هـى سـوى عمليـات جدلية

إذن بالنسبة للكتاب الكارولينجيين ولأوغسطين وبؤثيوس، تعد الفنون نماذج أزلية

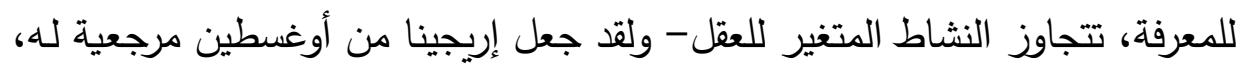
ولكنـه قدم منظومـة مختلفـة عن المعرفـة لم تطور من قبل خلفائه. فلقد جعل من التصـنيف الثلاثـى للفنـون الحـرة أو الفلسـفة والـذى يتمثـل فـى الأخـاق والفيزيـاء والمنطق، جعلـه تقسيـًا ربـاعى، وذلك مـن خـلال دمـج علم اللاهوت فـى نظـام الفلسفة84. من البين تتبع إريجينا منهج أوغسطين فى تبنيه للجدل الأفلاطونى، منحيًا

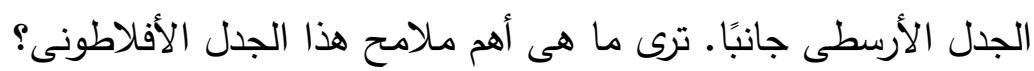
الجدل عند أفلاطون هو المنهج المؤدى إلى المعرفة العقلية الموجودة فى عالم

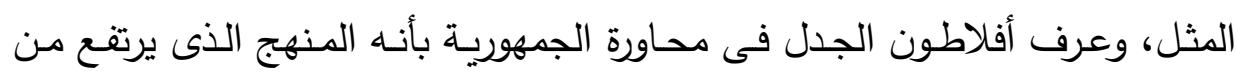
المحسوس إلى المعقول عبر الانتقال من فكرة لأخرى بواسطة فكرة، دونما الحاجة

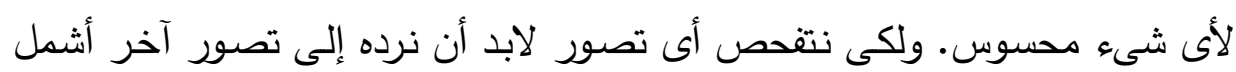

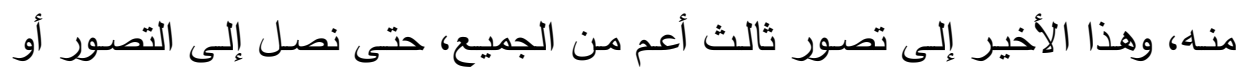

82 - Ibid,P131.

83- Ibid, P123-124.

84- Ibid, P 130. 
المثال الأعلى وهو مثال الخير • وللجدل طريقين: صاعد وهابط5.85. ولقد لعب الجدل

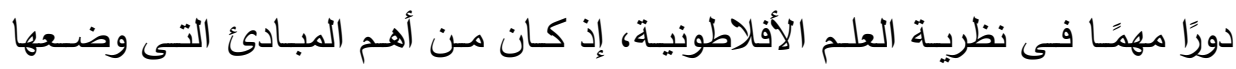
أفلاطون ليتم بواستطها الوصول إلى المثل التى يسعى إليها العلم، والتى تمثل العالم الثابت الواحد لكل العوالم المتغيرة.86. وإيمانًا من إريجينا بإمكانيات العقل وقدراته وكذا الجدل وأهميته، استخدمه فى لـ نطاق الطبيعة، فمسألة الانبثاق والعودة واللذان يحدثان على المستوى الميتافيزيقى، المجرد من التاريخ الزمنى، ولعل هذا يشرح الكيفية التى ينظر بها إريجينا إلى مكانة

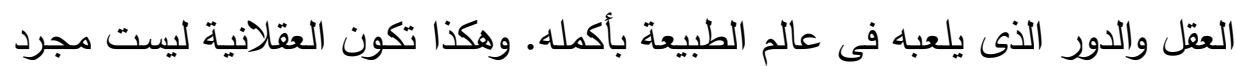
إحدى الهبات الموروثة للإنسان، بقدر ما هى ميزة إلهية، وانفتاح على التجربـة. وهى

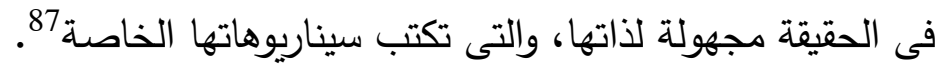
فإن الفلسفة بالنسبة لإريجينـا تصبح أداة ووسيلة العقل نفسـه، معبرة عن حياة العقل الإنسـانى فى حركاته الجدلية أثناء الانبثاق والعودة، وتتكثف وتتطـابق فى

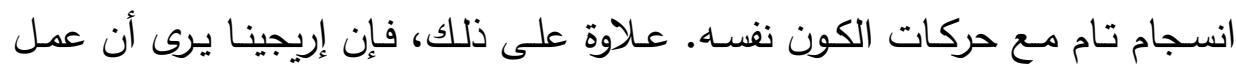
الفلسفة يرتبط ارتباطًا وثيقًا بنشاط العودة إلى الله، فالروح تعود إلى الله من خـلال الفلسفة 88.

إن مـنهج إريجينـا الجدلى الـنى يطوره فـى مسـألة الطبيعـة مـن خـلال فكرتى

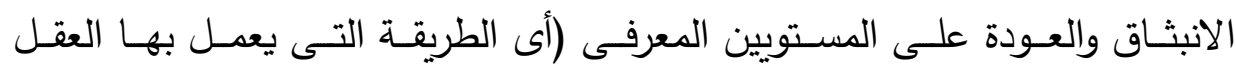

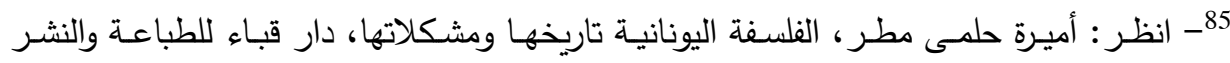

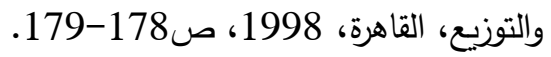
86- مصطفى النشار ، نظرية العلم الأرسطية، دراسة فى منطق المعرفة العلمية عند أرسطو، دار المعارف، ط2، القاهرة، 1995، ص48-49-4

87- Dermot Moran,Wandering from the pass,opcit,P100.

88- Dermot Moran, The Philosophy of John Scottus Eriugena ,op.cit, P124. 


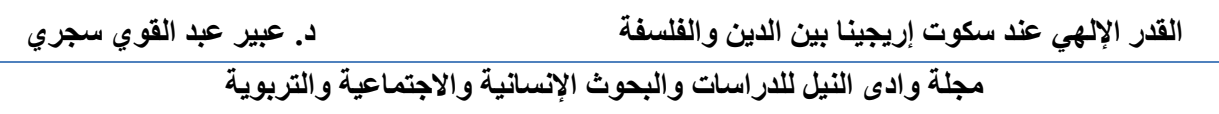

الإنسانى)، أو الأنطولوجى (طريقة بنيـة الواقع). فى الحقيقة ثمـة علاقة تداخل فى

فكر إريجينا بين الواقع من جهة وماهيات البنيات الواقعية للعقل الإنسانى 89. فنظام الطبيعة عند إريجينا لا يحرر العقل الإنسانى من سجن المكان والزمان الثابتين فقط، إنما يطور فكرة قديمة، وهى أن الطبيعة فى ذاتها تخضع لإعادة إعمار Reconstruction الإعمار فى الاستخدام الإنسانى للجدل السلبى المفارق. بعبارة أخرى، يسمح إريجينا

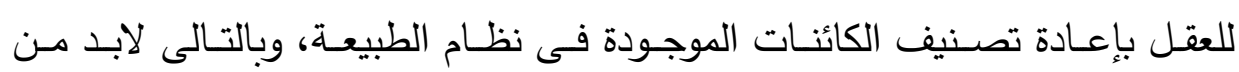
خضوعها للأنظمة الفكرية والعقلية90. فإن الفلسفة بالنسبة لإريجينـا تصبح أداة ووسيلة العقل نفسـه، معبرة عن حياة العقل الإنسانى فى حركاته الجدلية أثثاء الانبثاق والعودة، وتتكثف وتتطـابق فى ولئ

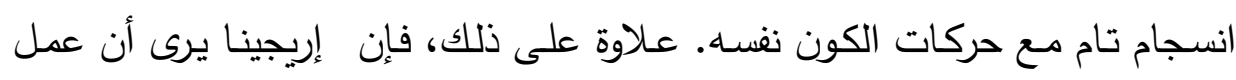

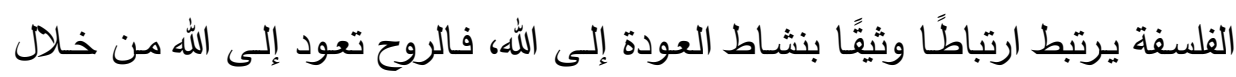
الفلسفة 91

يتضح مما سبق مكانة الفلسفة البارزة عند إربجينا، إذ يضعها جنبًا إلى جنب

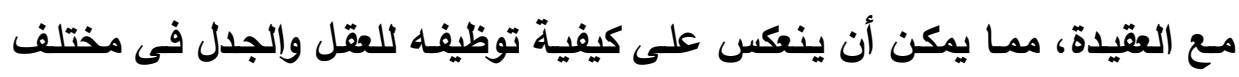
المسائل التى تعن له. - اله

\section{ثانياً: مشكلة القدر الإلهى}

89-See:Deirdre Carabine,John Scottus Eriugena,op.cit,P29.

90- Dermot Moran, Nature and Mind in the philosophy of John Scottus

Eriugena: Astudy in Medieval Idealism,PH.D,Yale university,1986 ,P19-20.

91- Dermot Moran, The Philosophy of John Scottus Eriugena ,op.cit, $\mathrm{P} 124$. 
يعود الحديث عن مسـألة القدر الإلهـى المسبق إلى أوغسطين فى رده على البلاجيوسية، حيث مال إلى المبالغة فى التأكيد على الاعتماد الإنسانى الكامل على العى النعمة الإلهية God's Grace وبالتالى فنحن مجبرين من قبل الله ولسنا أحرارًا 92. ولم ينكر أوغسطين وجود الثر فى العالم، وعكف على البحث عن مصدره فيقول:

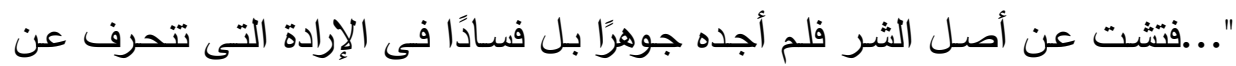
الذات السامية- عنك يا إلهى - إلى ما هو دني" "93.

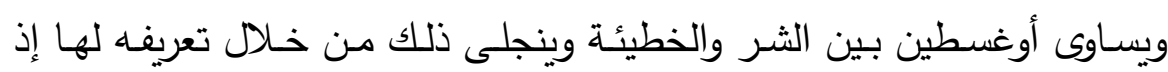

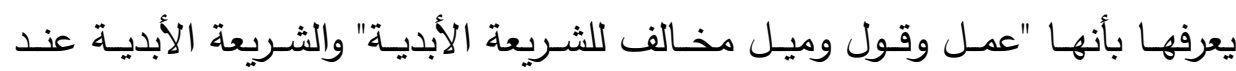

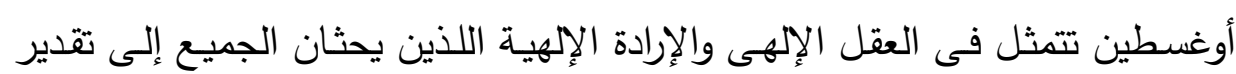

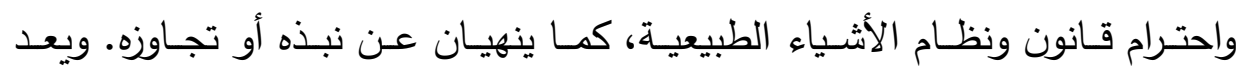
أوغسطين الخطيئة شرًا فى الإنسان وفوضى حقيقية. والخطيئة تجعل الإنسان يحيد عن الخالق الأسمى ويتجه نحو الكائنات الدنيوية 94. فالخير هو السير بمقتضى القانون الطبيعى أو الإلهى أما الثر فهو مخالفة هذا

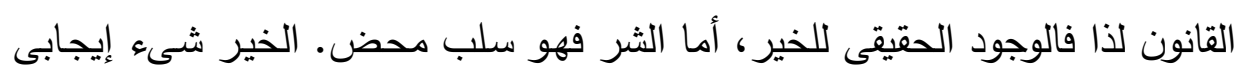
أما الثر فهو نقصان 95.

* لقد تناول إريجينا أطروحته عن القدر الإلهى وصاغها فى كتابه "رسالة حول القدر الإلهى" من خلال تسعة عشر فصلًا. 92- Ibid, p29.

93- أوغسطينوس أسقف هيبون، الإعترافات، الكتاب السـابع، نقله للعربية الخورى أسقف يوحنـا

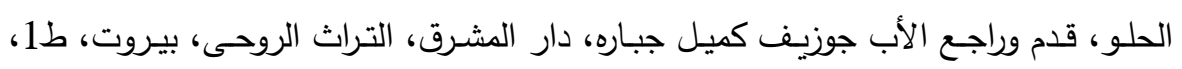

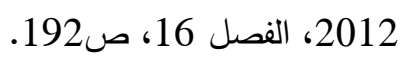

94- أوغسطينوس، خواطر فيلسوف فى الحياة الروحية للقديس أوغسطينوس، نقلها للعربية الخورى

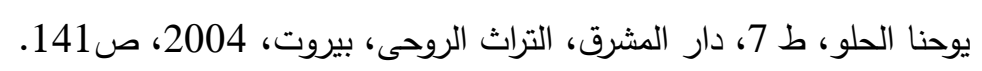

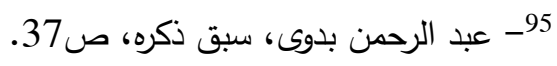




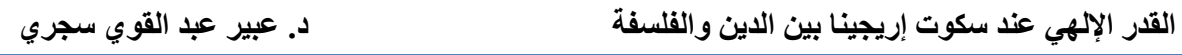
مجلة وادى النيل للاراسات والبحوث الإنسانية والاجتماعية والتربوية

وتوصـل أوغسطين إلى أن الفاعـل الحقيقى للشـر هو النـاس الأشـرار • يقول:

"بالطبع إن الثـر لا يمكن أن يحدث بدون موجد. لكن إذا سـألت عن ماهيـة هذا الموجد، لا يمكن منحك إجابة، إذ ليس هنالك موجد واحد فقط، بالأحرى إن البشر

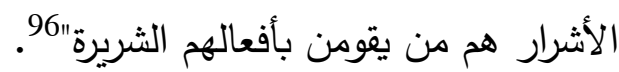

هذا مجمل موقف أوغسطين من الشر والخطيئة، ذلك الموقف الذى فتح باب التساؤل حول مسألة القدر الإلهى، حيث وجد أوغسطين نفسه مرغمًا على تتاول تلك المسألة خاصة وأن التساؤل حول مشكلة القدر الإلهى المسبق انبثق بصورة طبيعية عن النقاش حول موضوع الشر والخطيئة الموجودين فى العالم. 1- الاختيار الهر للإرادة الفردية همدر الخطيئة:

يناقث إريجينا فى رسالته فى القدر الإلهى كيف أن الله خير تام، ويريد إنقاذ جميع البشر ولا يجبر النفوس على الخطيئة، بل على العكس البشر يلعنون أنفسهم من خلال خياراتهم الحرة"97. يؤكد إريجينا أنه ليس هناك مصدر أو سبب للخطيئة ولا للشر سوى الإرادة الفردية للإنسان الذى يسئ استعمال الاختيار الحر 98 لا يستطيع الله أن يقدر مسبقًا شئ على الإرادة الإنسانية، فإن الناس يباركون أو

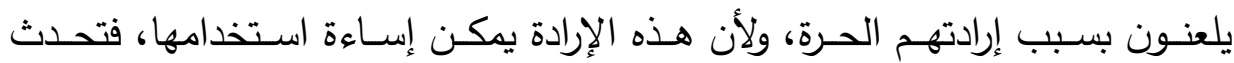

96- Augustine, On the free choise of the will,on the grace and free choise,and other writings,Edited and trans;by Peter King,university of Toronto,Cambridge text in the history of philosophy, Cambridge press,2010, Book1,1.1.1.3,p3.

97-See: Dermot Moran, John Scottus Eriugena, Standford Encyclopedia of Philosophy, Op.cit, P5.

See also: Dermot Moran, john scottus eriugena, Encyclopedia of medieval philosophy, Springer,Verlag, Ireland, 2010, p2.

98_ John Scottus Eriugena, Treatise On Divine Predestination,op.cit,p 41. 
الأخطاء الفردية 99. ويقول أيضًا: "...بالنسبة لكل إرادة تخلو من الفساد، فهى أفضل

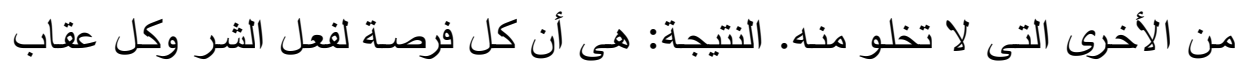

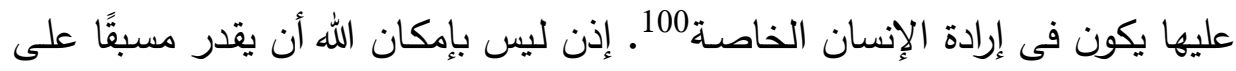

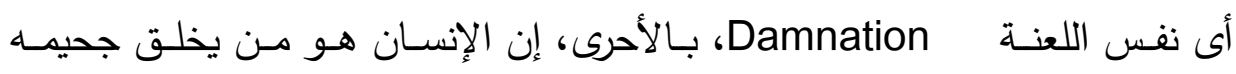

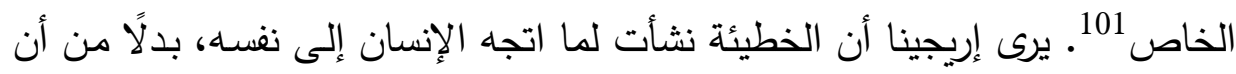
يتجه نحو الله 102.

ويقر إريجينا بلجوئه لاستخدام الجدل وآلية المقارنة والتثبيه لإيضاح ذلك: أولاً: من الحماقة الاعتقاد بأن ليس هناك ما هو أعلى من الإرادة الإنسانية، لاسيما أنها

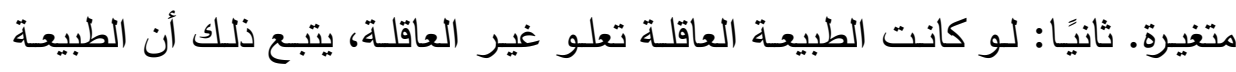

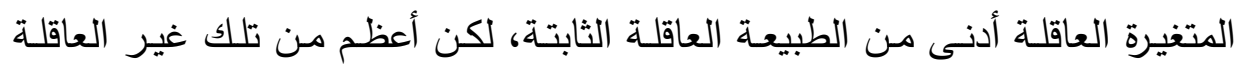

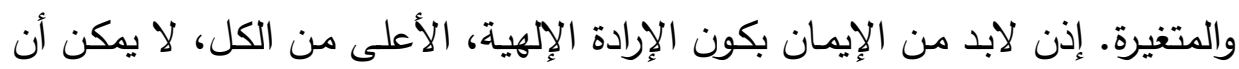

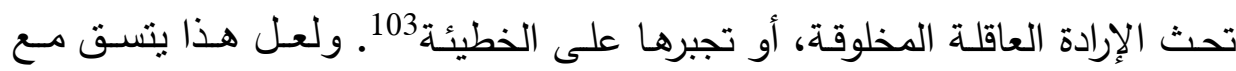

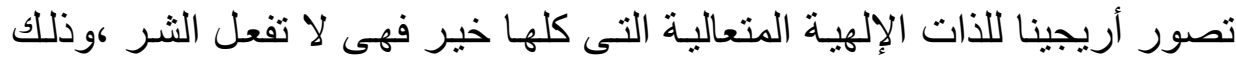
لأن الثر سلب للوجود.

ولا شك أن وجهـة نظر إريجينـا حول الإرادة الفردية بوصفها مصدرًا للخطيئة

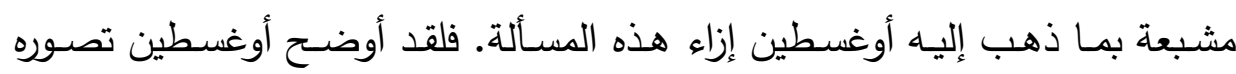

99- Andrea Elizabeth,Eriugena On Predestination and Dialectics,Fild under dialectics or east $v$ west ,John Scotus Eriugena, Philosophy, Predestination,St Maximus,2009,p1.

100_ John Scottus Eriugena, Treatise On Divine Predestination, Op.cit, p43.

101_Andrea Elizabeth, Op.cit, p1.

102- راسل، تاريخ الفلسفة الغربية، سبق ذكره، ص158.

103_ John Scottus Eriugena, Treatise On Divine Predestination, Op.cit ,p41-42 
الأساسى لـلإرادة فى كتابه "فى الاختيار الحر" من خـلال ثـلاث أطروحات: أولها:

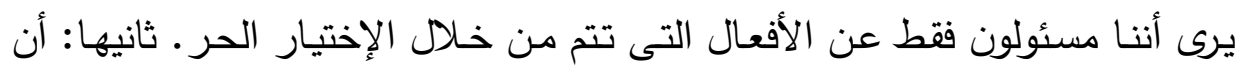
الإرادة ذاتيـة التحديد تمائا، بمعنى أنـه لا وجود لعلـة أو إرادة مسبقة تحدد لـلإِرادة الإنسـانية إختياراتها الحرة. ثالثها: نحن مسـئولون عن عدم امتلاكنـا لإرادة خيـرة، وحصولنا على إرادة حرة يقع تحت نطاق قدرتنا104*.

يؤكد أوغسطين امتلاك آدم لإرادة حرة قبل السقوط، وكان بإمكانه الامتناع عن إن

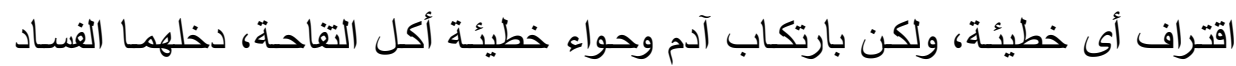
الذى انتقل منهما إلى خلفهما كله، ولم يعد بإمكان أحد الامتتاع عن الخطيئة بقوته الخاصة؛ وبالتالى فلا سبيل أمام الناس إلى حياة الفضيلة إلا برحمة من الله، وبوراثة

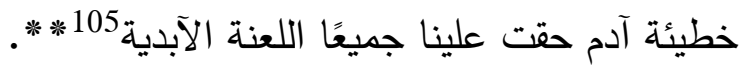

104-See: Augustine, On the free choise of the will,on the grace and free choise, and other writings,op.cit,Pxix.

*- يرى "جون كاوبورن "أن موقف أوغسطين مـن الإرادة الإنسانية متدرج عبر مراحل حياته،

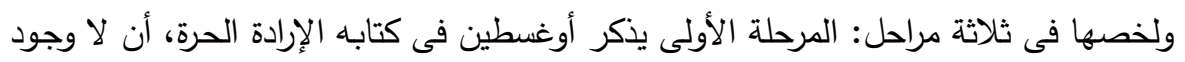

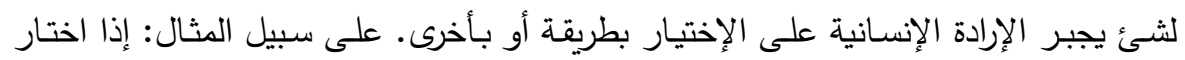

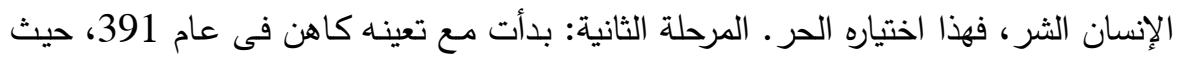
قال أن البشر فى بداياتهم كانوا قادرين على الإختيار بين الخير والثر ، ولكن نتيجة ارتباطه

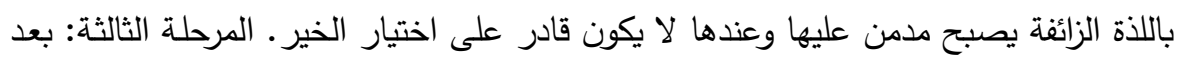

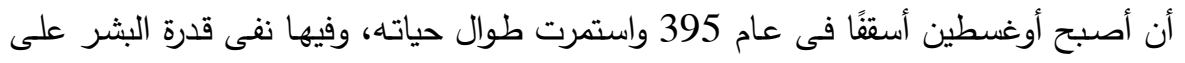

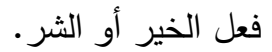

See: john cowburn,free will,predestination and Determinism,Marquette univ;press,2008,P90.

$$
\text { 105- راسل، تاريخ الفلسفة الغربية، سبق ذكره، ص95. }
$$

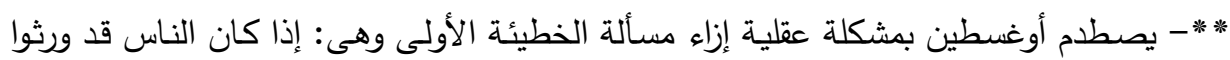

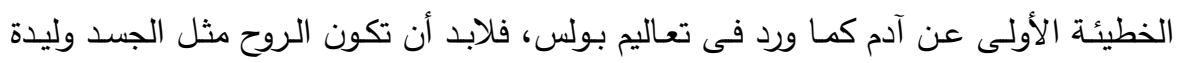




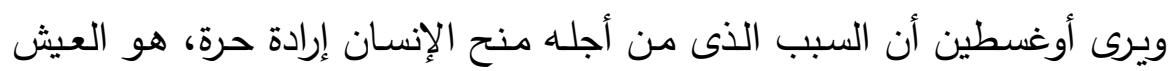

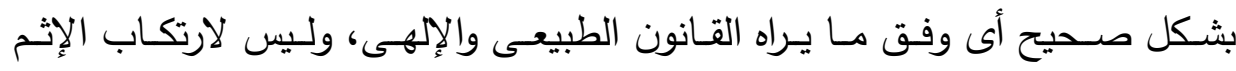

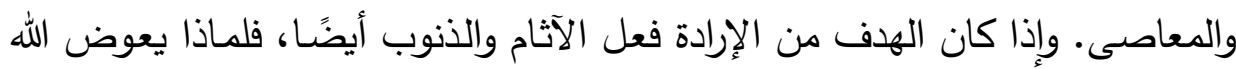

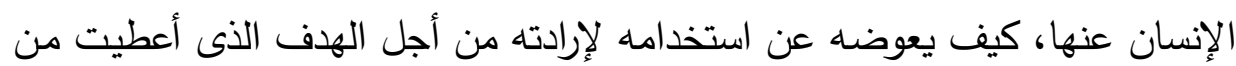

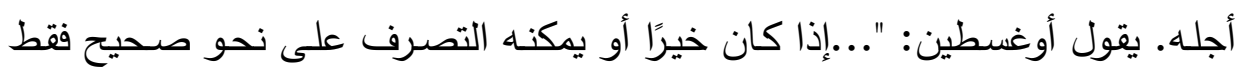

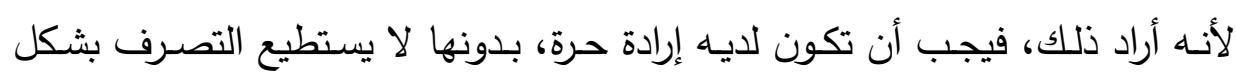

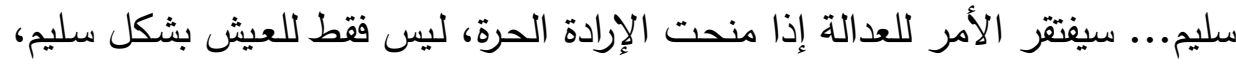

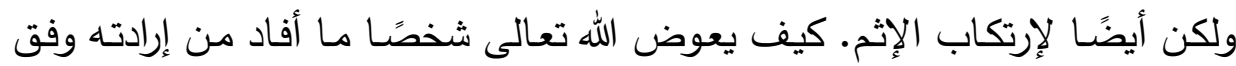
الغرض الذى أعطيت له؟"106.

ويشير أوغسطين إلى العدالة الإلهية تتطلب وجود إرادة حرة للإنسان*، لأن عند

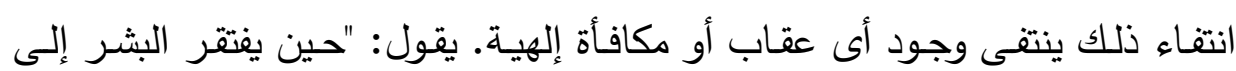
الاختيار الحر للإرادة، فكيف يكون ثمة وجود للخير الذى بموجبه تتم الإثشادة بالعدالة

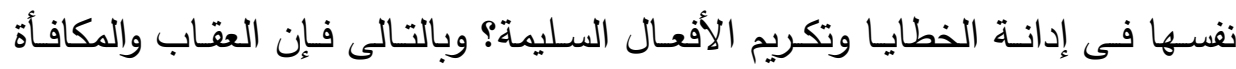
ستكون غير عادلة إذا لم يكن للبشر إرادة حرة"107.

الأبوين، ذلك لأن الخطيئة خطيئة روح لا خطيئة جسد. لكن أوغسطين رأى أن هذه المسألة الكئة

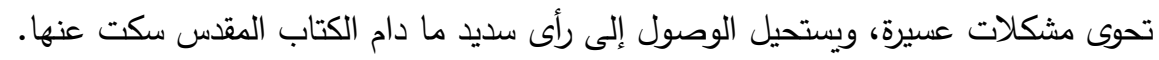

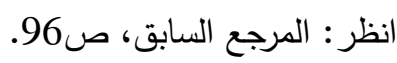

106 Augustine, On the free choise of the will,on the grace and free choise, and other writings,op.cit, Book2,2.1.3.5,2.1.3.6,P31,32.

" - عندما حاول أوغسطين التوفيق بين الغاية الإلهية والحرية، حاول الفرار من الإجابة عن هذا السؤال،

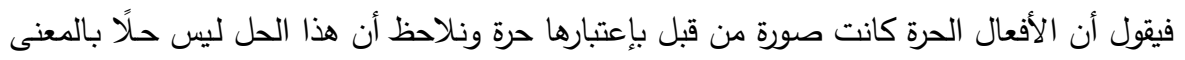
الصحيح، بل هروب فحسب.

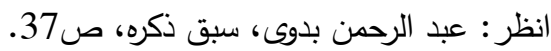
107_: Augustine, On the free choise of the will, on the grace and free choise, and other writings,op.cit,Book2,2.1.3.7,P32. 
وأقر أوغسطين بقدرة الإرادة الإنسانية على الاختيار بين ما هو أعلى أو ما هو

أدنى، وبرغم ذلك، وبسبب ضعف الطبيعة الساقطة Fallen Nature، فإنها تميل بشكل عام إلى الأشياء الأدنى، والتى تتمثل فى ملذات الجسد 108 يقول أوغسطين:

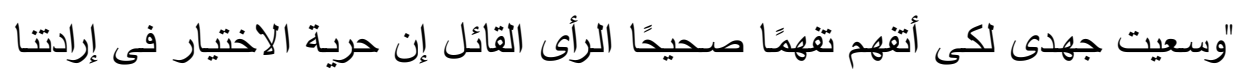
هى علة شرورنا، وأن الإنصـاف المرعى فى أحكامك هو سبب آلامنا. ولمـا تيقنت

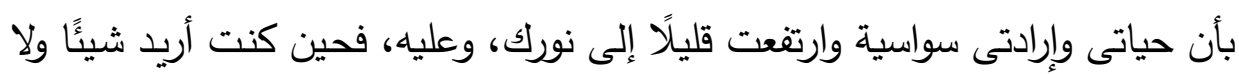

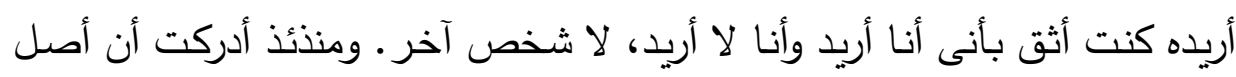

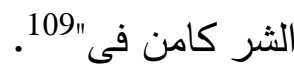

مجمل القول، لقد اجمع كل من أوغسطين وإريجينا على العامل الرئيسى لوقوع الإنسان فى الخطيئة، وهو الإختيار الحر للإرادة الفردية.

2- تعريف القدر الإلهى:

القدر Predestination- كما جاء فى القواميس- هو الإعتقاد بأن الناس ليس

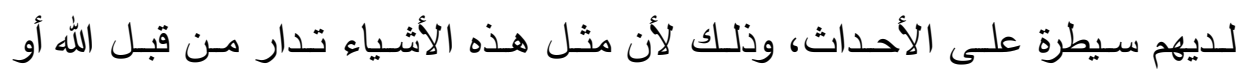

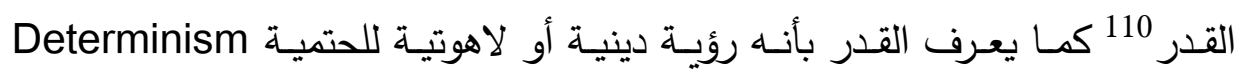

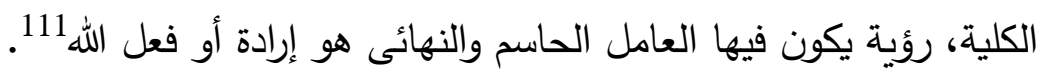

108 - See:- Dermot Moran, The philosophy of John Scottus Eriugena, op.cit, p30.

109- أوغسطينوس أسقف هيبون، الإعترافات، سبق ذكره، الكتاب السابع، الفصل الثالث، ص173. 110-The editors of Cambridge Dictionary, Predestination, Cambridge Advanced Learner's and Thesaurus Dictionary, Cambridge univ; press, 2019.

111- Mavrodes, George I, Predestination, Routledge Encyclopedia of Philosophy, London and New york, 2000, P706. 
مجلة وادي النيل للاراسات والبحوث الإنساتية والاجتماعية ـ مجلة علمية محكمة

(ISSN : 2536 - 9555)

ويرصد إريجينا تطور موقف أوغسطين من القدر الإلهى عبر مراحل حياتهـ112.

ويعرض إريجينا لتعريفات أوغسطين للقدر ـ فلقد منح أوغسطين عدة تعريفات للقدر

الإلهى المسبق، ومنها كون القدر هو تصرف الله الأوحد فى الأحداث حسب معرفته

المسبقة113، يقول أيضًا: "...بناءً على ذلك أحيانًا نفس القدر تتم الإشارة إليه تحت لتص اسم المعرفة الإلهية المسبقة"114.

ويربط أوغسطين بين القدر وبين النعمة Graes، إذ يرى أنه لا يوجد سوى فرق إل

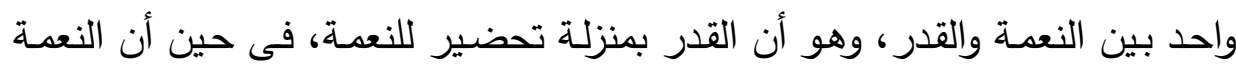

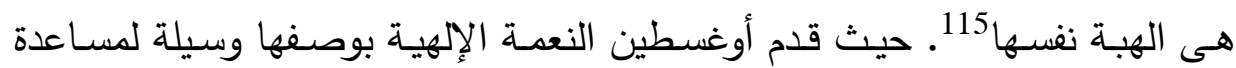
الإرادة الحرة على اختيار الخير. ومع ذلك انتقل تدريجيًا إلى موقف أكثر تطرفًا وهو الإه أن البشر يعتمدون كليًا على النعمـة الإلهيـة فـى كل فعل وقرار • وعلى هذا النحو سيكون بعض الناس مقدر لهم بإرادة الله أن يكونوا منقذين، وبعضهم الآخر مقدر لهم

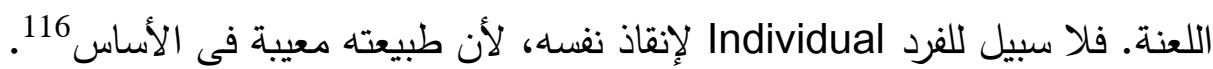
انطلق إريجينـا مـن التعريفات التى قدمها أوغسطين لمصطلح "القدر" مقتبسًا العديد من الاقتباسات من كتابات أوغسطين نفسه، وخاصة التعريف الذى يوضح من

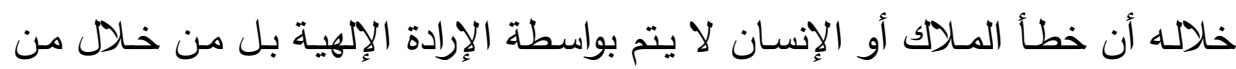

112 - See: John Scottus Eriugena, Treatise On Divine Predestination, op.cit, p74.

113 - See: St Augustine, on the predestination of the saints and on the gift of perseverance, trans; by The Rev.Ernest wallis, Revised by Benjamen B.Warfield, Taken from "The early church fathers and otherwork", Scotland Beginning, 1867, book2, ch41, p53.

114- St .Augustine, on the predestination of the saints and on the gift of perseverance, Op.cit, Book2, ch47, p57.

115 - St .Augustine, on the predestination of the saints and on the gift of perseverance, Op.cit, Book1, ch19, p14.

116 - Dermot Moran, The philosophy of John Scottus Eriugena,op.cit,p30 
أراد الفعل. ويعترف إريجينـا بـأن سـاع القـول بأن المقدرين للنـار الأبديـة معدون لغضب الله ومقدرين للموت الأبدى ومقدرين للدمار وغيرها من الكلمات المشابهة، قد تؤودى إلى الضـلال. ومن يسمع مثل هذه الكلمات سيعترف دون تردد بنوعين من

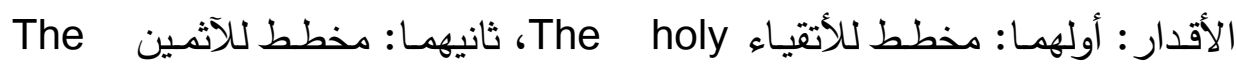
unholy وهذا ما يرفضسه العقل 117.

ثم يعرض إريجينا تعريف أوغسطين للقدر، الذى يربط فيه بين القدر والمعرفة الإلهية المسبقة. ويدون ملاحظته عليه، وفحواها كيف أن تعريف من هذا النوع يأتى يُن من خلال التمييز بين نوعين من الأجناس 118. ولا شك أن إريجينا بهذا قد وجد من خلال كتابات أوغسطين، أن أوغسطين يقر بكون الله يقدر مسبقًا للشرير الجحيم أو العقاب وقد يختلف الناس حول فهم هذه الكلمـات. ولكى يقف إريجينـا على حقيقـة موقف أوغسطين أكد إريجينـا ضـرورة

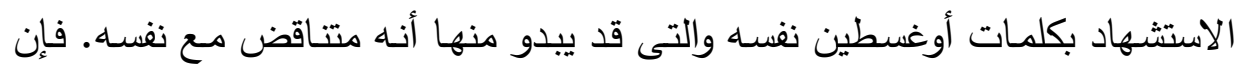
القارئ الفطن وحده يمكنه الانتباه إلى أى نوع من اللغة يستخدم أوغسطين حين يقول إن القدر الإلهى المسبق خصص لكل فئات البشر ، النعمـة للمختارين والعدالة

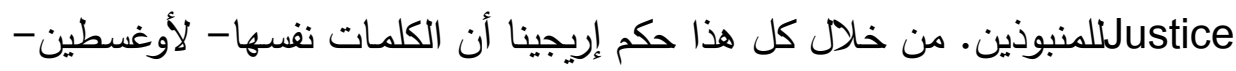
تستخدم بشكل سئ من قبل الزنديق لكى يؤيد أفكاره الخاطئة 119. هذا هـى تعليقـات إريجينـا على مـا قدمسه أوغسطين مـن تعريفـات لمصطيح "القدر".فكيف جاء تعريفه للقدر ؟

117- see: John Scottus Eriugena, Treatise On Divine Predestination, Op.cit, p75.

118 - Ibid, p76.

119 - Ibid, p74. 
يبدأ إريجينـا تعريفهـ للقدر بـالإقرار بأن الاختلاف بين القدر المسبق والمعرفة المسبقة، يعنى أن كل قدر يكون معرفة مسبقة، وليس كل معرفة مسبقة تكون قدر . ولكن المعرفة المسبقة، والتى يعرف الله من خلالها مقدمًا ما سوف يفعله هو نفسـه تكون حقيقية، ويطلق عليها بشكل محدد "القدر". بينما المعرفة المسبقة، التى يعرف بها الله مقدمًا الأشياء التى لم يفعلها والتى تتمثل فى الخطايا وعقوبتها فهى ليست قدر ، فالمعرفة المسبقة وحدها التى يطلق عليها قدر هى ما تفهم دائمًا بمعنى خِير • ولكن المعرفـة المسبقة وحدها بـدون القدر تخص الأشياء الشـريرة التى لا يفعلها

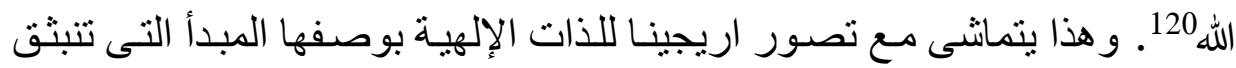

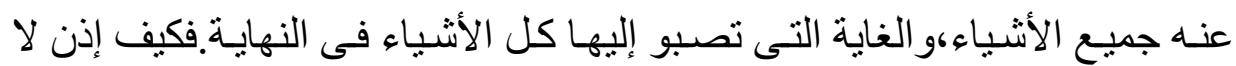

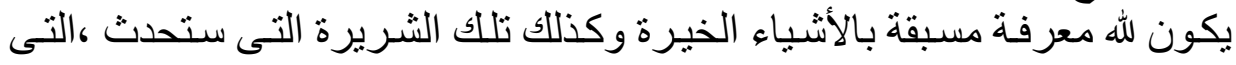

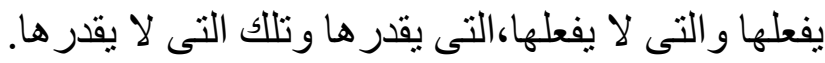

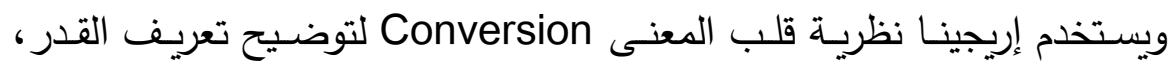

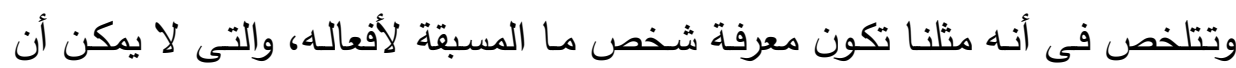
تكون خاطئه أو قابلة للتتغير ، إذ يرتب هذا الشخص وينظم أفعاله المستقبلية، وقطعًا

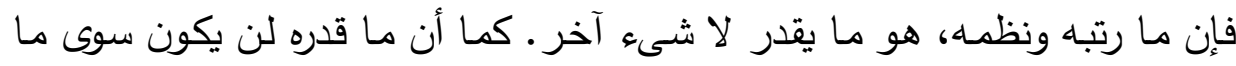

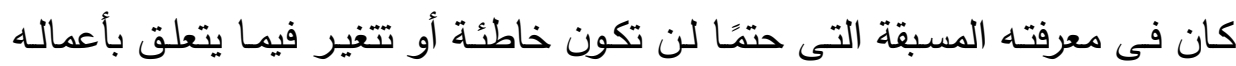
المستقبلية. يطبق إريجينا هذه الفكرة على الذات الإلهية، فإذا كانت كل معرفة مسبقة والتى تقرر أعماله المستقبلية تكون قدرً إلهيًا، عندها كل القدر والذى من خلاله يقرر أعماله المستقبلية، يكون معرفة إلهية مسبقة؛ ويتبع ذلك أن قدر الله ليس له وجود إلا فى أعماله 121. والحقيقة أن تعريف إريجينا هذا لم يكن مبتكرًا، حيث إن أوغسطين قد سبقه إليه أيضًا، حيث ذهب هو كذلك إلى أن القدر المسبق لا يوجد بدون علم مسبق، بينما

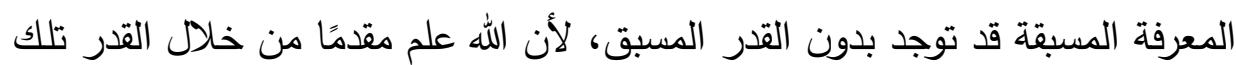

120 - Ibid, p76.

121 - Ibid, p77. 


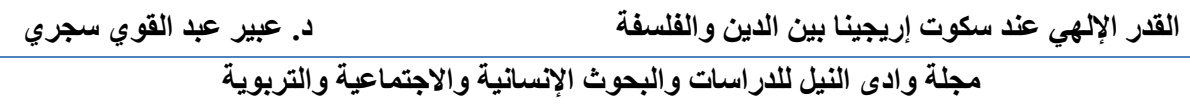

الأشياء التى كان على وشك القيام بها. كما أنه أيضًا بمقدوره أن يعرف مسبقًا تلك الأشياء التى لا يفعلها هو نفسه أى الخطايا والآثام. القدر الإلهى المسبق للخير هو

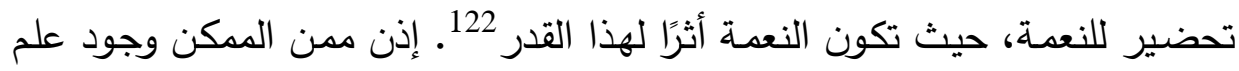
إلهى مسبق بدون قدر، بينما لا وجود للقدر فى غياب العلم الإلهى المسبق.

3- اعتماد إريمينا على الفلاففة والجدل لإثبات عدم ازدواجية القدر الإلهى:

لقد شـرح إريجينـا وجهـة نظره الخاصـة وهـى استحالة وجود نـوعين من القدر ، وجادل بأن أخطاء جوتشالك الجسيمة ونابعة من افتقاره لتعلم الفنون الحرة 123 ـولقد عول على الفلسفة والجدل للبرهنة على انتفاء وجود ازدواجية فى القدر الإلهى. كما استخدم حجة الضرورة لإثبات ذلك.

إن طريقة إريجينا للخروج من هذا الموقف الصعب تقوم على فكرة الأفلاطونية

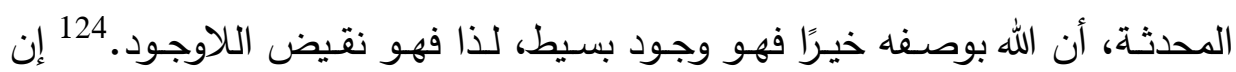
إزدواجية القدر لا تتفق مـع خيريـة الله ووحدته، إن بساطة الذات الإلهية تجعل القدر واحد 125.

يستحضـر إريجينـا الوحدة الإلهيـة والمفارقـة والخيـر الأبـدى للتأكيد على عـدم

إمكانية وجود نوعين من القدر، فطبيعة الله واحدة وكذلك predestination قدره 126. ويقـول إريجينـا: "...ويتبــع ذلـك لــو أن كـل الأشـياء التهى تحمـل على الله تكـون

122 - St .Augustine, on the predestination of the saints and on the gift of perseverance, op.cit, Book1, ch19, p14,15.

123 - John Christian Macinnis, The Harmony of all things: music, sool, and cosmos in the writings of John Scottus Eriugena, florida state uni; PH.D, 2014, p19.

124- Andrea Elizabeth, Op.cit, p1.

125- Wayne Hankey and Lloyd D P.Gerson, Op.cit, p832.

126 - Dermot Moran, John Scottus Eriugena, Encyclopedia of medieval philosophy, op.cit, p2. 
مجلة وادي النيل للاراسات والبحوث الإنساتية والاجتماعية ـ مجلة علمية محكمة

(ISSN : 2536 - 9555)

واحدة،.... ولا شىع يحمل على الله أكثر من القدر، لذا فهو واحد"127. ولقد سبق . . واستخدم إريجينا هذا الإفتراض الميتافيزيقى عند تتاوله لمسألة الثر، حيث ذهب إلى أن الله جوهر واحد "Una Substania" ليس بـ أى أثر للثنائية، فإن نظريـة القدر المزدوج هى فى الأساس خطأ حول طبيعة الله 128. يقدم إريجينا حجج عقلية على استحالة القول بإزدواجية القدر الإلهى. منها قوله: "أولًا: إن العقل الحقيقى يوصى بكون الإرادة الإلهية هى المبدأ الأعلى والعلة الوحيدة لكل الأشياء التى صنعها الأب من خلال حقيقته، وأن هذه الإرادة نفسها بكل السبل الإنى الإدهل خالية من أى ضرورة، والتى إما تجبرها أو تعيقها، ولكن تكون هى نفسها ضرورتها، وبالتالى فهى إرادة كلية"129.

Effects to" ويدلل إريجينا أيضًا على موقفه بحجة أخرى توصف "مؤثرات العلة

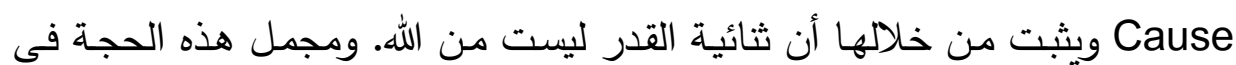
القضية القائلة "الأشياء المتقابلة بالتبادل Mutually، يجب بالضرورة أن تكون عللها متقابلة بالتبادل". فنقيض الوجود هو اللاوجود، ونقيض الحياة الفناء. هذه الأشياء المتعارضة بالتبادل عللها تكون أيضًا متعارضـة بالتبادل، بالتالى لو أن هنالك نوعين من القدر الإلهى يصدران من علة واحدة وهى الله، أم أن هناك علة أخرى فى طبيعة

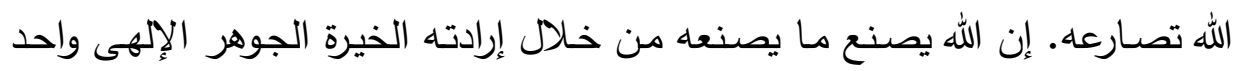
غير مقسم لأجزاء ومن ثم فلا يمكن أن يكون القدر مقسم إلى جزئين. فإن العقل إنل العهن يمنع أن تكون هناك علة واحد أو علتين من النوع نفسه، لهما تأثيرات مختلفة

127- John Scottus Eriugena, Treatise On Divine Predestination, Op.cit, p18.

128 - Dermot Moran, Nature and Mind in The philosophy of john scottus Eriugen, op.cit, p302.

129 - John Scottus Eriugena, Treatise On Divine Predestination, Op.cit, p17.

130_ Ibid,p21 


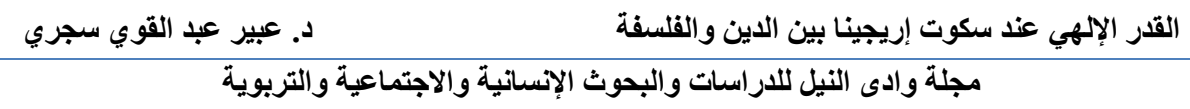

كما يستخدم إريجينا حجة الضرورة، وينطلق من مبدأ عدم وجود ضرورة فى الذات الإلهية، بمعنى أن الله يفعل ما يفعله بإرادته الحرة ليس ثمة شىع يدفعه بالضرورة للقيام بما

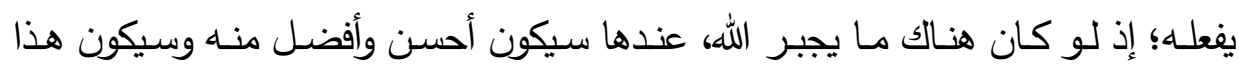
الثيء أجدر بالعبادة بوصفه إلهًا وعلة أسمى لكل الأشياء 131. ويقول إريجينا: "...أين يمكن أن نجد نوعين من القدر الإلهى الذى يؤكد عليهما جوتثالك؟ إن العقل الحقيقى True لا يسمح بوجودهما فى الله ... وذلك بسبب قوة الضرورة... وبالرغم حقًا من أن كل الأشياء ... التى أرادها الله... تحتاج إلى وجوب لهاب

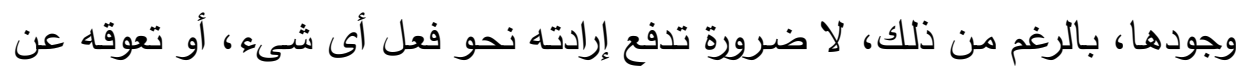

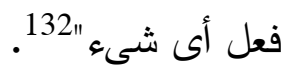

وبعد أن دحض هذه المسألة بالعقل، يبدأ فى توضيح مدى جرم القول بإزدواجية

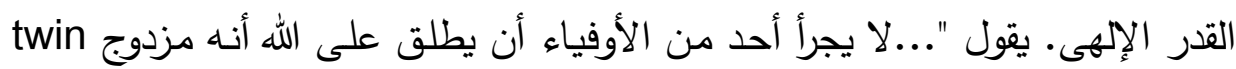

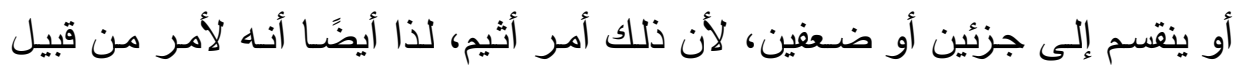
تدنيس المقدسات إعلان أن القدر والمحبة charity الإلهية الأبويـة يكونوا مزدوجين أو يضـعفونها أو يقسمونها إلى قسمين... فمـن يؤمن بـاله يحتاج لأن يؤمن أيضًا

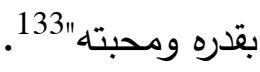

إن إريجينا يرى أن وجود الله هو حكمته، والله لله معرفة واحدة فقط، وبالتالى لا يمكن أن ننسب إليه القدر المزدوج predestination ومن جهة أخرى فإن الطبيعة البشرية خلقت عاقلة، والعقلانيـة rationality تتطلب الحريـة، إذن الطبيعـة البشريـة حرة

\footnotetext{
131 - Ibid,p11

132_ Ibid,p15

133 - Ibid,p21

134 - see: Dermot Moran, John Scottus Eriugena, Standford Encyclopedia of Philosophy, Op.cit, p5.
} 
من الجلى أن إريجينا وإن اعتمد على العقل فى البرهنة على عدم امكانية القول بنوعين من القدر الإلهى؛ فـلا يمكن إغفال كون ذلك تم فى ضـوء تصـوره الذات

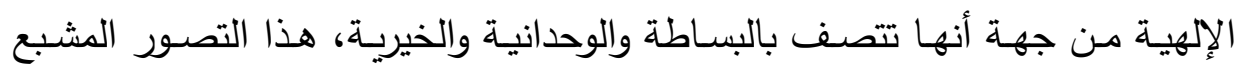
بالمؤثرات الدينية والمدشن على قواعد عقلية فلسفية.

\section{4- القدر والعلم الإهى المسبق:}

بدايَّة يؤكد إريجينا على أن وجود القدر الإلهى والمعرفة الإلهية المسبقة، لا تعنى أن الإنسـان مجبر على فعل الخير أو فعل الثـر. وهذا يتضـح من عنونته للفصل الإنى الخامس من رسالته حول مسألة القدرب "المعرفـة المسبقة والقدر الإلهى لا يعنيان

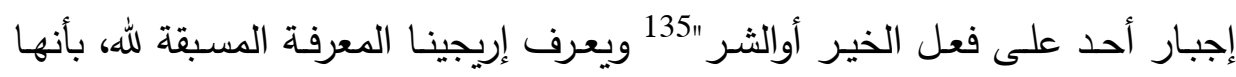
تعنى التنبؤ بما يمكن للإنسان القيام بـه من آثام مستقبلية، ومعرفته هذا لا تعنى أنـه هو من يقوم بهذه الآثام 136.

فـإن معرفته المسبقة يمكن أن تكـون خيـرة فـى ذاتها، وهذه المعرفـة لا تجبـر Predestine توضيح كيف أنه لا يوجد قدر Predestination نحو الشر ـ فلا يمكن القول بأن الله يعرف الثر على الإطلاق 138 ـوأكد أن كل من الثر والخطيئة سلب لا وجود حقيقى لهما، لذا لا يمكن أن يكونا بسبب الله 139. ويرى إريجينا المعرفة الإلهية المسبقة والقدر الإلهى لا يحدان من حرية الإنسان. فإن معرفة الله المسبقة لا تجبر أحد على ارتكاب الثر ، فإنه كذلك لا يجبر أحد على الإلى لإنه 135 - see: John Scottus Eriugena, Treatise On Divine Predestination, op.cit, p30.

136_ Ibid, p33

137- Dermot Moran, The philosophy of John Scottus Eriugena,op.cit,p31

See also: Dermot Moran, Nature and Mind in The philosophy of john scottus eriugena, Op.cit, p302.

138 - Dermot Moran, The philosophy of John Scottus Eriugena,op.cit,p31

139- Andrea Elizabeth, Op.cit, p1. 


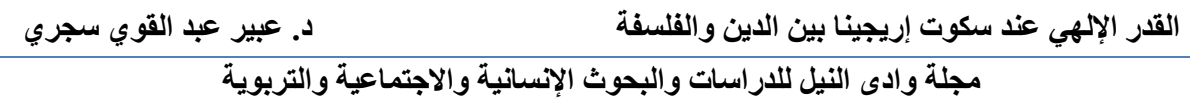

الاستقامة، لأن ذلك يتنافى مع حرية الإرادة الإنسانية. يقول: "...فى هذه الأثناء لابد

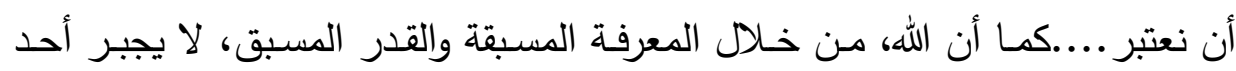

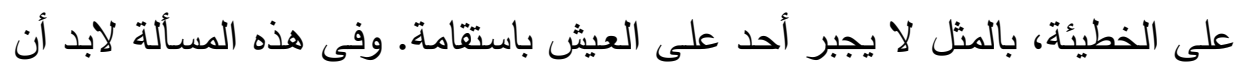
يفهـ أنـه ليس هنـاك حريـة حقيقيـة لأى إرادة، لو أن بعض العلـل تفرض بإكراه...

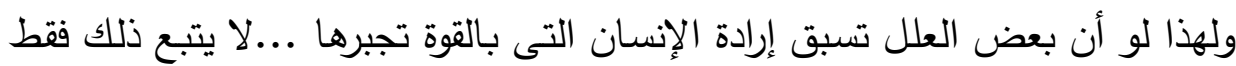
أنها ليست حرة ...ولكن ليست حرة على الإطلاق 140". هذا ما سبق وجزم به أوغسطين، حيث أكد أوغسطين على أنها ليس ثمـة تناقض

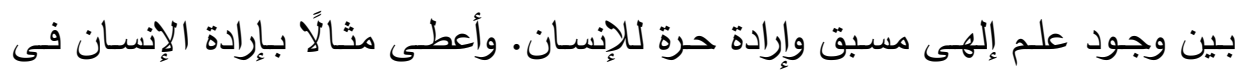
السعادة Happeness أو استحقاق اللوم Blameworthy. فعلم الله المسبق بإرادة الإنسـان نحو السعادة أو اللوم، لا يقف حجر عسر بين الإنسـان وبين تحقق هذه الإرادة. وها هو يقول: "...على الرغم من كون الله يعلم مسبقًا إرادتنا المستقبلية، فلا يتبع ذلك أننا لن نفعل شينًا بمله إرادتنا... وبرغم ذلك أؤكد لك أنها حين تكون سعيدًا، فهذا لن يكون ضد إرادتك ولكن عن طيب خاطر ... إن معرفة الله المسبقة بالسعادة المستقبلية (وهو الأمر المؤكد حتى اليوم) لا يعصف بإرادتك فى السعادة فى إنى

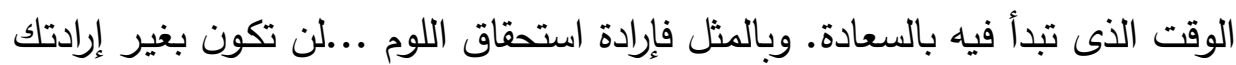

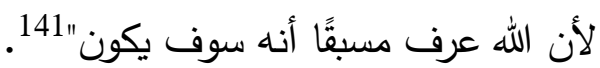
وهكذا بعد تأكيد إريجينا- أسوة بما ذهب إليه أوغسطين - على القول بنوع واحد من القدر الإلهى يخص القديسين، نجده يجزم بإمكانية وجود حريـة إنسانية فى ظل بل وجود القدر الإلهـى، وكيف لا، خاصـة إذا فهم القدر بمعنى العلم الإلهى المسبق، وبالتالى فهم العلم الإلهى المسبق بمعنى المعرفة المستقبلية لما يفعل الإنسان.

140 - John Scottus Eriugena, Treatise On Divine Predestination, Op.cit, p35.

141 - Augustine, On the free choise of the will,on the grace and free choise,and other writings,op.cit,Book3,3.3.7.27:3.3.7.29,P78. 
مجلة وادي النيل للاراسات والبحوث الإنساتية والاجتماعية ـ مجلة علمية محكمة

(ISSN : 2536 - 9555)

\section{الخاتمة}

لقد حاولنا فيما سبق الوقوف على ماهية معالجة إريجينا لمشكلة القدر الإلهى. وثمة عدة ملاحظات على هذه المعالجة نجملها فى التالى:

أولًا: لم تحظى مشكلة القدر الإلهى عند إريجينا بالقدر الكافى من التناول أو هُه المعالجة من قبل المفكرين والباحثين المنشغلين بالفكر الوسيط، إذ كان جل اهتماههم بما قدمه إريجينا من آراء تتعلق بالطبيعة. ثانيًا: لقد أثر تصور إريجينا للذات الإلهية على موقفه من القدر الإلهى،فالذات

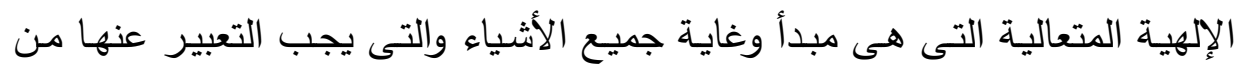
خلال الصفات السلبية، هى خير محض، لا تقدر سوى الخير ولا يمكن أن تقدر الثر على الإنسان، كما أنها لا يمكن أن تحد من حرية الإنسان. ثالثًا: يرى البعض أن غرض إريجينا من هذه المعالجة هو الحفاظ على أمرين: القدر الإلهى والنعمة هذا من ناحية، والحرية الإنسانية من ناحية أخرى 142. خـلال التقحص الدقيق لتتاول إريجينـا لمشكلة القدر الإلهى لم نجده يفرد مسـاحة

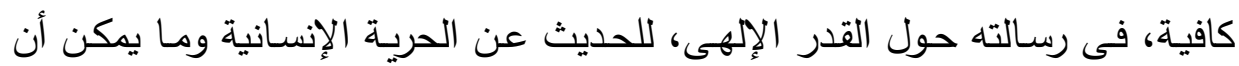
يمسها عند الإقرار بالقدر الإلهى المسبق. رابعًا: لم يظهر إريجينا نفسه فى معالجته لقضية القدر الإلهى كديالكتيكى ماهر فقط، ولكن كمفسر ماهر لأوغسطين 143. فلقد سار على خطاه وحذى حذوه؛ بل كان

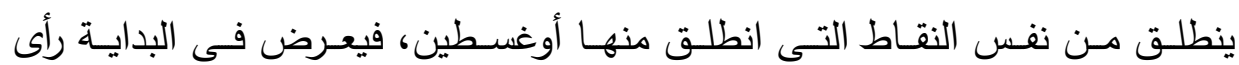
أوغسطين ثم يشرع فى إبداء موقفه من هذه النقاط. وكيف لا فلقد كان إريجينا مولعًا بأراء أوغسطين ومواقفه، فجعل منه سلطة مرجعية كبرى لله، تنير غياهيب ظلمات العديد من الموضوعات الثائكة التى كان يتعاطى معها؛ وليس أدل على ذلك من وصفه لأوغسطين بالعبارات الأتية: "يعد الأب الروحى أوغطين حقًا أكثر المؤلفين

142 - See: Lloyd.P.Gerson(ed), op.cit, p831.

143 - Dermot Moran, The philosophy of John Scottus Eriugena, op.cit, p32. 


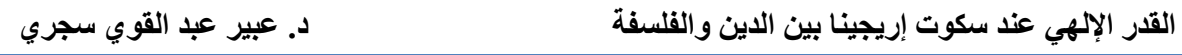
مجلة وادى النيل للاراسات والبحوث الإنسانية والاجتماعية والتربوية

خصوبة فى البلاغة المسيحية، وهو أكثر باحث لديه مهارة البحث عن الحقيقة، كما أنه شارح نبيل موضوعى يتسم بالإستخدام المتتوع للغة من أجل رقى قرائه"144. خامسًا: لقد وصف البعض فلسفة إريجينا بكونها تمثل استثناءً صارخًا من فكر أصيل ومبتكر لم يصل إليه أحد من معاصريه، ولم يقدر أحد من اللاحقين عليه أن أن أن يواصله؛ بل أن إريجينا قد انتج أعظم منظومة فكريـة فى العصور الوسطى كلها 145. ولعل هذا ينطبق على ما قدمه إريجينا من آراء تتعلق باللاهوت والطبيعة وأقسامها، ولكن - بناءً على ما سبق -لا يمكن إطلاق مثل هذا الرأى إزاء تتاوله لمسألة القدر الإلهى، فلا أثر للأصالة أو الإبتكار فى هذا التناول. سادسًا: إن أطروحة إريجينا فى كتابه "رسالة حول القدر الإلهى" قد ذهبت أبعد من الهدف الذى دشنت من أجله، فلقد حارب إريجينا من خلالها آراء جوتشالك كما

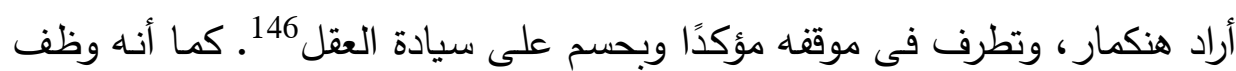

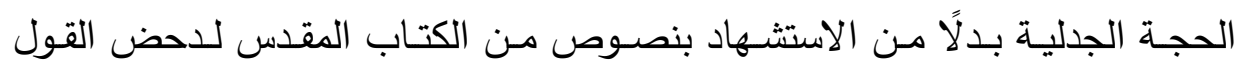
بإزدواجيـة القدر 147. فلقد عول إريجينـا على الفلسفة والجدل بشكل مبالغ فيـه ازاء معالجته لمسألة القدر الإلهى وذلك على حساب استخدامه الدين ونصوص الكتاب المقدس والتى كان يستعين بها على نحو ضئيل، وذلك مقارنة بتوظيفه للفلسفة وآلية الجدل للتدليل على وجهة نظره الخاصة.

يتضح من كل ما سبق كيف عالج إريجينا إشكالية القدر الإلهى، فهو من جهة: رجـل ديـن مسيحي، لـم يكـن بمقدوره غض الطـرف عـن مـا ورد بكتـاب المقدس

144_ John Scottus Eriugena ,Treatise On Divine Predestination, Op.cit, p 73.

$$
\text { 145 - كوبلستون، سبق ذكره، ص159. }
$$

146_ See: John Lord,Beacon lights of history,Vol.V,(In 15 volumes), The Middle Ages, Originally published in 1883, Cosimoclassics, Newyork, cover copyright 2009, P202.

147_ Dermot Moran, john scottus eriugena,Encyclopedia of medieval philosophy, op.cit, p2. 
بخصوص هذه المسألة. ومن جهة أخرى: مفتون بالفلسفة فأفسح المجال أمامها، كما أطلق العنان للعقل وقدراته، بصورة أغضبت رجال الدين آنذاك. والغريب في الأمر أن إريجينا- فى مشكلة القدر الإلهى- لم يهدف إلى توظيف كل من العقل والفلسفة

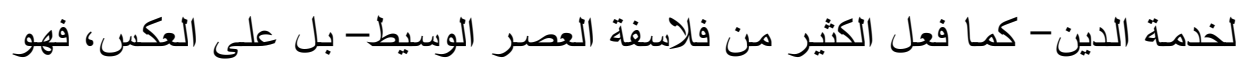
اهتم بتأويل ما ورد فى الكتاب المقدس من نصوص تتعلق بالقدر الإلهى لكى تتماهى

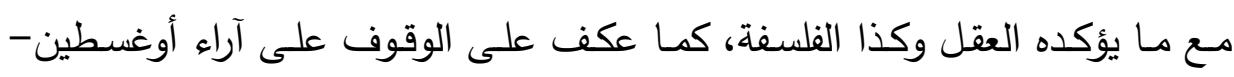
المتآرجحة والمتغيرة- التى تخص مسألة القدر الإلهى، واختيار ما يتوافق منها مـع وجهة نظره الخاصة والتى يرجحها العقل وتؤيدها الفلسفة، وذلك دون المساس بثوابت 
القدر الإلهي عند سكوت إريجينا بين الدين والفلسفة

\section{قائمة المصادر والمراجع}

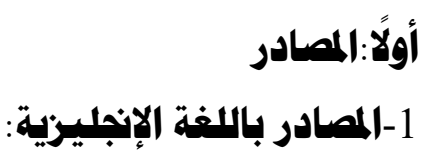

1- Augustine, On the free choise of the will, on the grace and free choise, and other writings, Edited and trans; by Peter King, university of Toronto, Cambridge text in the history of philosophy, Cambridge press, 2010.

2-Dionysius The Areopagite, Dionysius The Areopagite Works (1897), Mystic Theology, Caput 1, section 2, Trans by John Parker, Grand Rapids, Mi: Christian Classics Ethereal Library, London, 1897, Date Created: 2005.

3- Iohannis Scotti Erivgenae, Periphyseon, edited by I.P.SheldonWilliam, The Dublin Institute for Advanced Studies, Dublin, B1, 1968.

4- Iohannis Scotti Erivgenae, Periphyseon edited by I.P.SheldonWilliam, The Dublin Institute for Advanced Studies, Dublin, B2, 1972.

5- John Scottus Eriugena, Treatise On Divine Predestination, trans; by Mary Brennan, Notre Dame Texts in medieval culturs, vol 5, John Van Engen editor, the medieval institute, university of notre dame press, Indiana, 2002.

6-St Augustine, on the predestination of the saints and on the gift of perseverance, trans; by The Rev.Ernest wallis, Revised by Benjamen B.Warfield,Taken from "The early church fathers and otherwork", Scotland Beginning, 1867. 
مجلة وادي النيل للاراسات والبحوث الإنسانية والاجتماعية ـ مجلة علمية محكمة

(ISSN : 2536 - 9555)

2- المادر بالاغة العربية:

1- أوغسطينوس أسقف هيبون، الإعترافات، الكتاب السـابع، نقلـه للعربيـة الخـورى أسقف

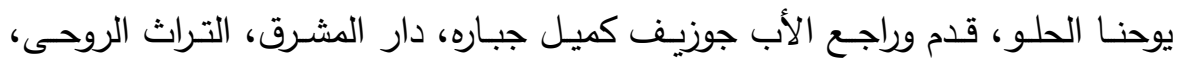

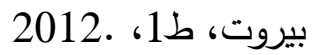

2- أوغسطينوس، خواطر فيلسوف فى الحياة الروحية للقديس أوغسطينوس، نقلها للعربية

الخورى يوحنا الحلو، ط 7، دار المشرق، التراث الروحى، بيروت، 2004.

\section{ثانياً: المراجع}

1- المراجع باللغة الإنجليزية:

1- Agnieszka Kijewska,Eriugena's De praedestinatione:The project of rationalization of faith and its critics, Roczniki Filozoficzne, Tom LXV,number 3,2017.

2- Deirdre Carabine, John Scottus Eriugena, Great Medieval Thinker, Oxfore uni; press, New york, 2000.

3-Deirdre Carabine, The unknown God, Negative Theology in Platonic Tradition: Plato to Eriugena, Peeiers press, Louvain, 1995.

4- Dermot Moran, The Philosophy of John Scottus Eriugena, (Astudy of idealism in the Middle ages) Cambridge university press, 1990 .

5- James Mcevoy, Happiness in the intellectual life, The Cambridge companion to Medieval philosophy, edited by A.S.McGrande.

6- john cowburn, free will, predestination and Determinism, Marquette univ; press, 2008. 
القلر الالهي عذد سكوت إريجينا بين الاين والفلسفة

7- John Lord, Beacon lights of history, Vol.V, (In 15 volumes), The

Middle Ages, Originally published in 1883, Cosimoclassics, Newyork, cover copyright 2009.

8- Wayne Hankey and Lloy D P.Gerson, John Scottus Eriugena,

The Cambridge History of Philosophy in Late Antiquity, vol ii,

Cambridge university press, 2010.

9- Willemien Otten, The Anthropology of Johannes Scottus

Eriugena, E.J.Brill, Leiden, NewYork, 1991.

\section{2- المراجع باللغة المربية:}

1- انظـر : أميرة حلمى مطر ، الفلسفة اليونانيـة تاريخهـا ومشكلاتها، دار قبـاء للطباعـة

والنشر والتوزيع، القاهرة، .1998

2- اميل برهييـه، تـاريخ الفلسفة، العصـر الوسيط والنهضــة، ج 3، دار الطليعـة للطباعـة

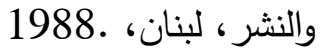

3- راسل حكمة الغرب، ج2، ترجمة فؤاد زكريا، عالم المعرفة، الكويت، عدد62، .1983

4- راسل، تاريخ الفلسفة الغربية، الكتاب الثانى، الفلسفة الكاثوليكية، ترجمـة زكى نجيب تردي

محمود، الهيئة المصرية العامة للكتاب، .2010

5- عبد الرحمن بدوى، فلسفة العصدور الوسطى، وكالـة المطبوعـات الكويت، دار القلم

لبنان، ط3، كبـ 1979.

6- كوبلستون، تاريخ الفلسفة، (من أوغسطين إلى دانز سكوت)، م 2، قسم 1، ترجمة إمام

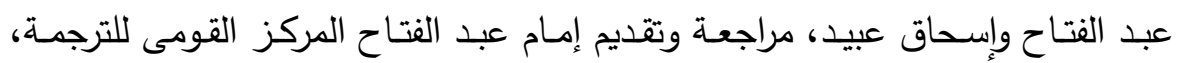

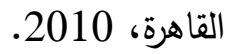

7- مصطفى النشار، نظرية العلم الأرسطية، دراسة فى منطق المعرفة العلمية عند أرسطو،

دار المعارف، ط2، القاهرة، 1995.

8- يوسف كرم، تاريخ الفلسفة الأوربية فى العصر الوسيط، الفلسفة الأوربية فى العصر

الوسيط، مؤسسة هنداوي للتعليم والثقافة، القاهرة، 2014. 
مجلة وادي النيل للاراسات والبحوث الإنساتية والاجتماعية ـ مجلة علمية محكمة

(ISSN : 2536 - 9555)

\section{ثالثا: القواهيس ودوائر المعارف والمالات والمجلات العلمية بالاغة الإنبليرية}

1- Andrea Elizabeth, Eriugena On Predestination and Dialectics, Fild under dialectics or east $v$ west, John Scotus Eriugena, Philosophy, Predestination ,St Maximus, 2009.

2- Dermot Moran, Eriugena, Johannes Scottus, in E.Craig(ed), Routledge Encyclopedia of philosophy, London, 2012.

3- Dermot Moran, Eriugena, John Scottus, Medieval Science, Technology And Medicine, An Encycolopedia, Thomas Glick, Steven. J.Livesey, Faith Wallis, Editors Research Gate, 2005.

4- Dermot Moran, John Scottus Eriugena, Encyclopedia of medieval philosophy, Springer, Verlag, Ireland, 2010.

5- Dermot Moran, John Scottus Eriugena, Standford Encyclopedia of Philosophy, Standford univ; Copyrights by Metaphysics Research lab, 2016.

6- Dermot Moran, Wandering from the pass: Navigatio in the philosophy of John Scottus Eriugena, The crane Bag, The other Ireland 1976, Published by: Richard Kearney, Jastor, 2017.

7- lise.A.schweitzer, Strange, Beauty: Ecocritical Approaches to early medieval landscape, by Alfred.K. Siewers, Review, oxford uni; Jastor, 2017.

8- Mavrodes, George I, Predestination, Routledge Encyclopedia of Philosophy, London and New york, 2000.

9- The editors of Cambridge Dictionary, Predestination, Cambridge Advanced Learner's and Thesaurus Dictionary, Cambridge univ; press, 2019. 
القدر الإلهي عند سكوت إريجينا بين الدين والفلسفة

10- William Turnner, John Scotus Eriugena, Catholic Encyclopedia, Edited by Kevin Knight, New Advent, 2012.

\section{رابعاً: راسائل الماجستير والدكتوراة باللاغة الإنهايرية}

1- Darren Hibbs, Eriugena, Berkeley, and Hegel: The variety of idealism in The western philosophical tradition, PH.D, univ; of Arkansas, 2001.

2- David C.Puxly, Soul as self and mediator from Plotinus to Eriugena, M.A, Dalhoosie Univ; Canada, 2005.

3- Dermot Moran, Nature and Mind in The philosophy of john scottus eriugena: Astudy in Medieval Idealism, PH.D, Yale university, 1986.

4- Jhon Chistian Macinnis, The Harmony of all things: Music, Sool, and Cosmos in The writing of, Florida state univ; PHD, 2014.

5- Julio Burunat, Faith and Reason in The thought of John scottus Eriugena, PH.D, Fordham university, New York, 1984.

6- Margaret P.Twomey, Towards enhanced divine- human-earth relation: Achristian- Buddhist contribution, PH.D, university college cork, Ireland, 2014. 